\title{
Designing Ergonomic Furniture Based on Students Anthropometry Attributes; College of Agriculture and Natural Resources, University of Tehran
}

\author{
Hossein Manouchehri', Payam Moradpuor ${ }^{2 *}$, Mohammad Amin Mououdi ${ }^{3}$, Ebrahim Aga-Rafiei ${ }^{4}$
}

1. MSc, Department of Wood and Paper Sciences \& Technology, Faculty of Natural Resources, College of Agriculture and Natural Resources, University of Tehran, Karaj, Iran

2. Assistant Professor, Department of Wood and Paper Sciences \& Technology, Faculty of Natural Resources, College of Agriculture and Natural Resources, University of Tehran, Karaj, Iran

3. Department of Occupational Health, School of Health, Mazandaran University of Medical Sciences, Sari, Iran

4. Faculty Member, Department of Wood and Paper Sciences \& Technology, Faculty of Natural Resources, College of Agriculture and Natural Resources, University of Tehran, Karaj, Iran

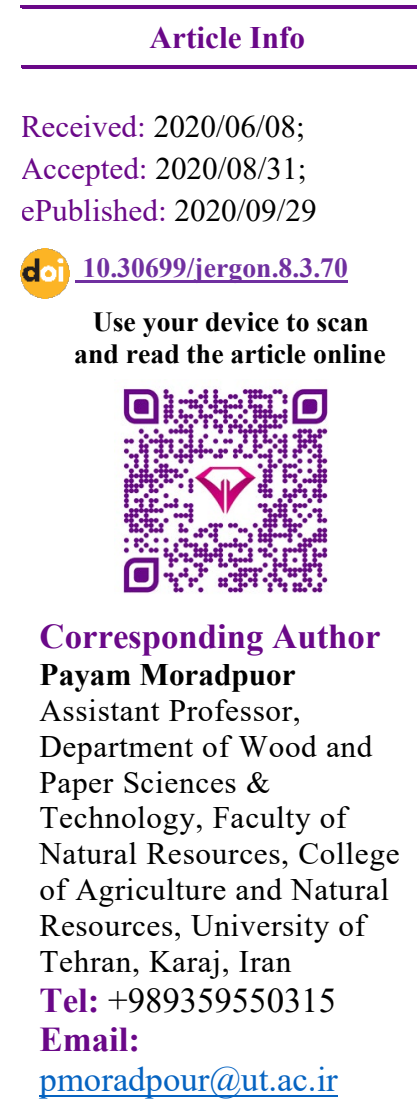

\section{ABSTRACT}

Background and Objectives: A well-designed desk and chair, in addition to proper learning, can prevent changes in the user's physical form. Therefore, this study aimed to determine the anthropometric characteristics of students in the College of Agriculture and Natural Resources located at the University of Tehran to design an ergonomic table and chair.

Methods: In this research, 18 anthropometric characteristics including the popliteal height, knee height, shoulder height, eye height, sitting height, elbow support height, elbow height, knotted elbow length, hip-popliteal length, hip-knee length, thigh thickness, abdominal depth, chest depth, hip width, shoulder width, the transverse width of the elbows, height, and as well as weight for 260 students (130 girls and 130 boys) aged 18 to 35 years were investigated. To collect data, an anthropometric chamber and chair were used. Finally, according to the measured physical dimensions of the students, the Dimensions of ergonomic table and chair were calculated and designed according to the INSO 9697-1 standard.

Results: Anthropometric dimensions of students were obtained through mean, minimum, maximum, standard deviation, mean, and the percentile value of 2.5 to 97.5 using SPSS version 20 software. The results showed that the age of the user does not have a significant effect on the size of the table and the chair. Also, the results showed that there was a significant difference in popliteal height between girls and boys.

Conclusion: Considering the difference in dimensions between female and male students, it was found that the popliteal height in the percentile of 5 for boys is $4 \mathrm{~cm}$ more than girls. Therefore, using measured anthropometric characteristics, the dimensions of the chair and table ergonomics were designed in two sizes.

Keywords: Anthropometric, Ergonomics, Percentile, Furniture, Students

Copyright (C) 2020, This is an original open-access article distributed under the terms of the Creative Commons Attribution-noncommercial 4.0 International License which permits copy and redistribute of the material just in noncommercial usages with proper citation.

\section{How to Cite This Article:}

Manouchehri H, Moradpour P, Mououdi M A, Aga-Rafiei E. Designing Ergonomic Furniture Based on Students Anthropometry Attributes; College of Agriculture and Natural Resources, University of Tehran. Iran J Ergon. 2020; 8 (3):70-84 
طراحى ميز و صندلى اركَنومى براساس تعيين مشخصههاى آنترويومترى دانشجويان: يرديس كشاورزى و منابع طبيعى دانشعاه تمهران

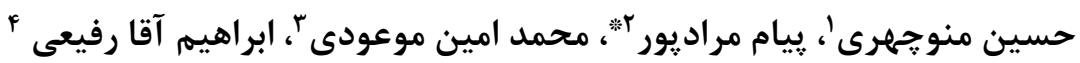

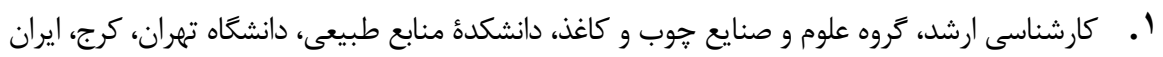

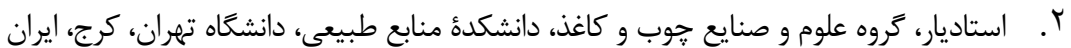

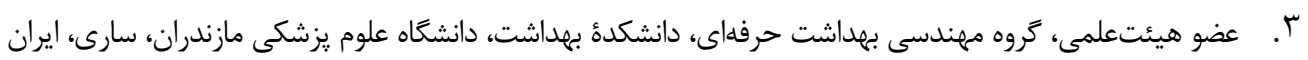

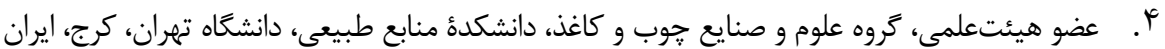

\begin{tabular}{|c|c|}
\hline خلاصه & اطلاعات مقاله \\
\hline 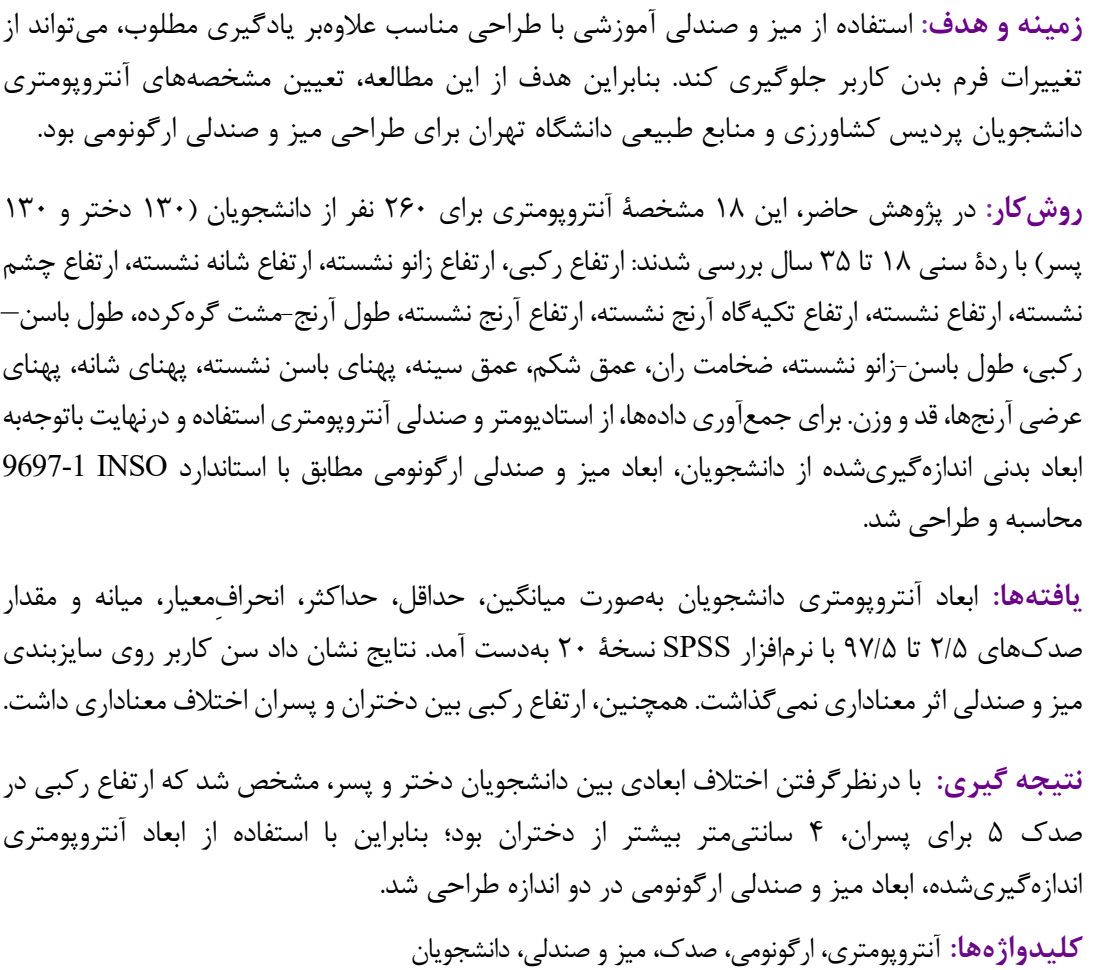 & 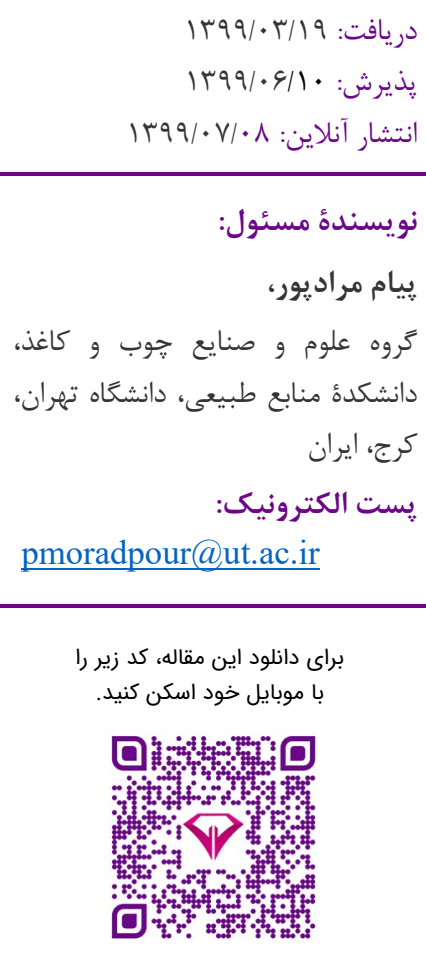 \\
\hline
\end{tabular}

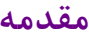

تفاوتهاى ابعاد انسانى در افراد مختلف يكى از دلايل مهم بررسىهاى آنترويومترى است؛ زيرا دادهاى آنترويومترى در بين افراد گوناگون،

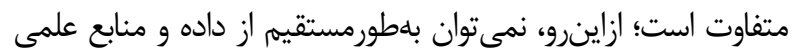
كشورهاى مختلف براى طراحى محصول ارگَونومى استفاده كرد. بنابراين، ارزيابى مشخصههاى آنترويومترى در طراحى محصى محصول

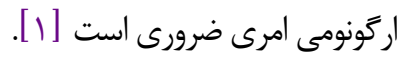
در اغلب كشورهاى جهان، بودجهُ مربوط به آموزش همواره با مشكلات زيادى مواجه است و همين موضوع سبب شده مسئولان
ارتقاى كيفيت زندگى ازجمله عوامل مهم در :ايدارى جوامع است كه ازطريق آموزش و يادگيرى بلهست مى آيد. ازآنجاكه پيايدارى رويكردى انسانمحور دارد، توجه به سلامت افراد در هر رده شغلى و

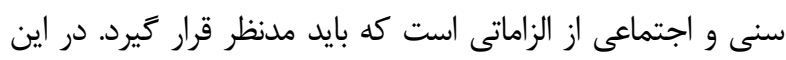
زمينه، ارگونومى (مهندسى عوامل انسانى) جايگاه ويزهاى دارد؛ جراكه

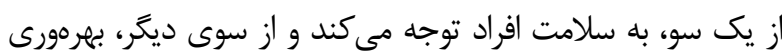
حرفهاى و عملكردى را افزايش مى مدهد. يكى از حيطههاى مطرح در بـ ارگونومى، كسب آكاهى از تناسب ابعادى يا آنترويومترى است. 
شهر تسالونيكاى يونان بلوضوح نشان داد كه بين ابعاد بدنى

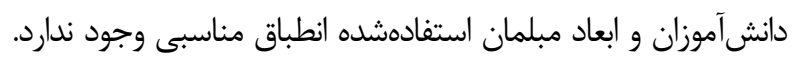
صندلىها براى شاكردان خيلى بلند و خيلى عميق و ميزها نيز خيلى بلند بودند؛ بلطورى كه اين مسئله مىتوانست تأثير منفى بر وضعيت

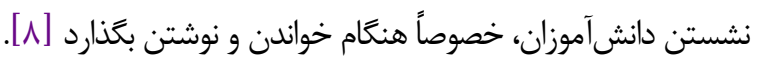
ستو Grimmer و Milanese

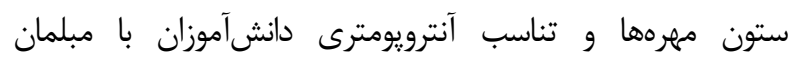

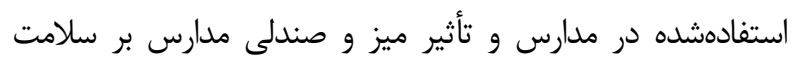

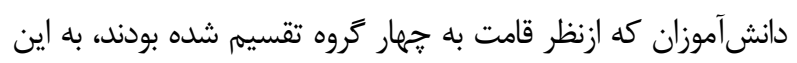

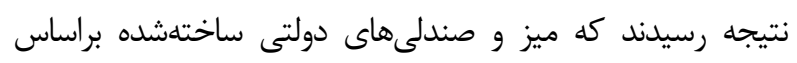

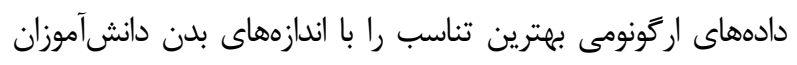

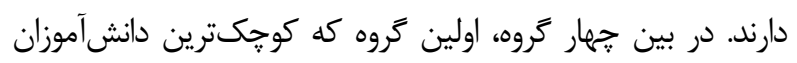

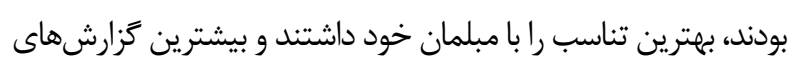

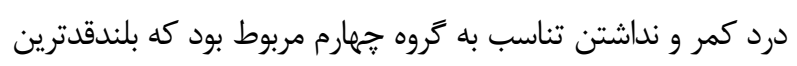

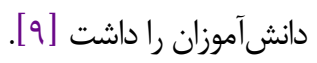
يروهش هاى Dianat و همكاران براى بررسى ميزان تطابق مبلمان

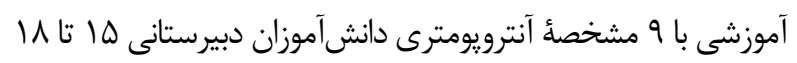

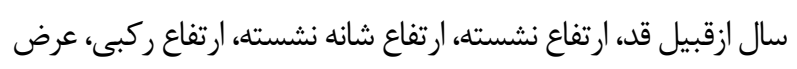

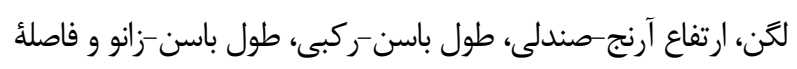

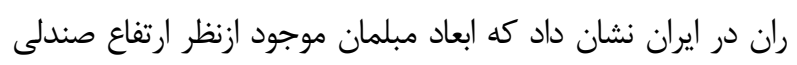

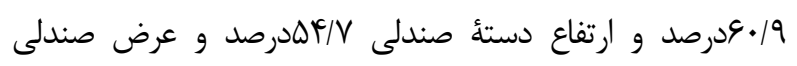

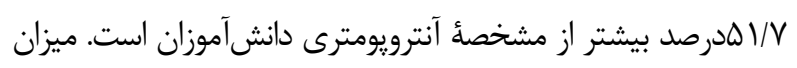

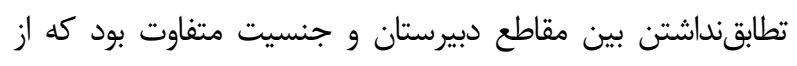

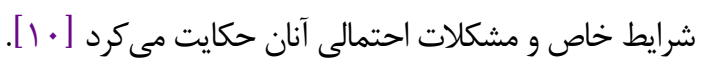

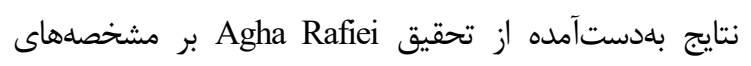

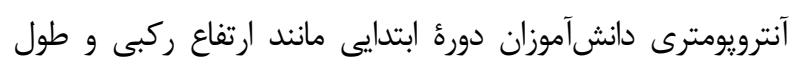

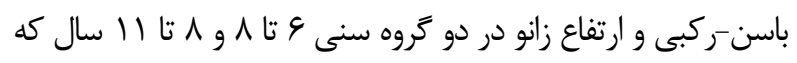

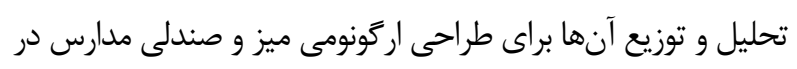

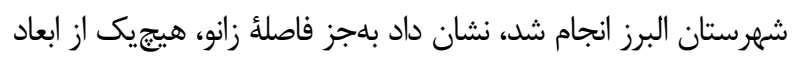

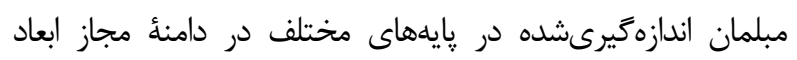

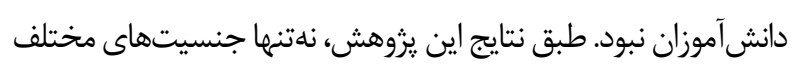

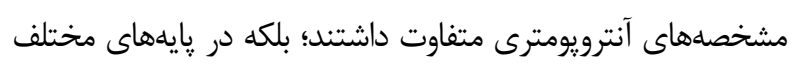

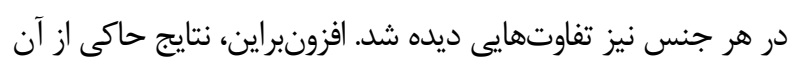

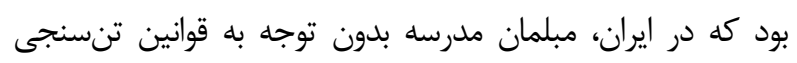

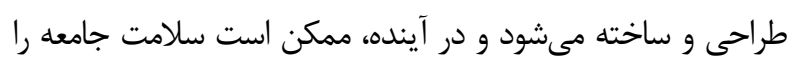

بهخطر بيندازد [11]
آكاهانه يا نآكاهانه به مبلمانهاى آموزشى اركّونومى كمتر توجه كنند

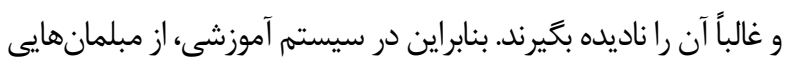

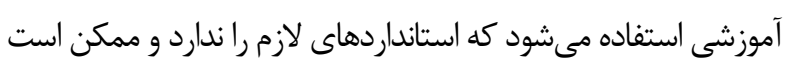

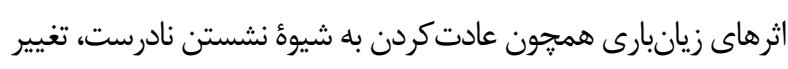

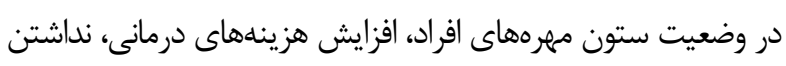

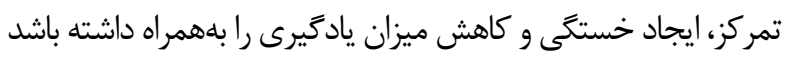

دانشآموزان بيشتر اوقاتشان در مدرسه را سر كلاسها و در

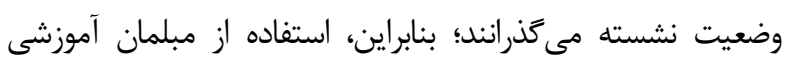

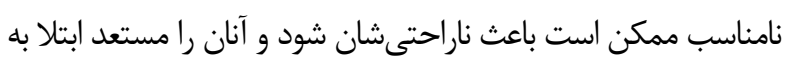

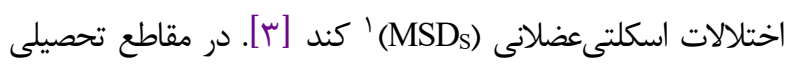

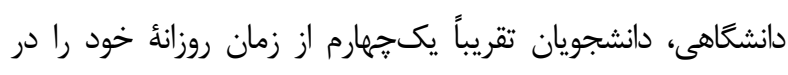

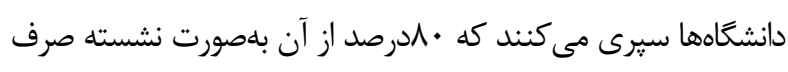

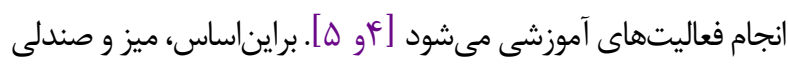

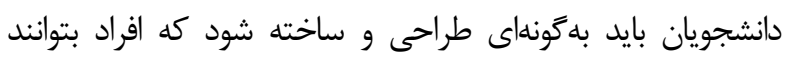

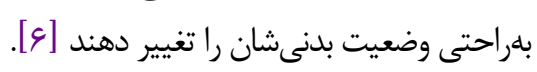

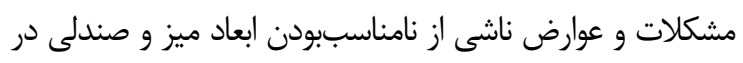

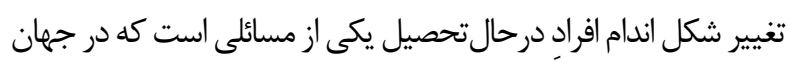

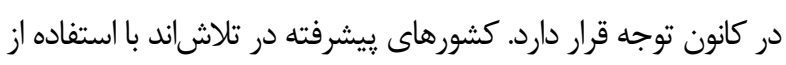

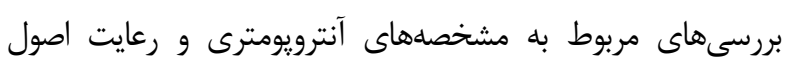

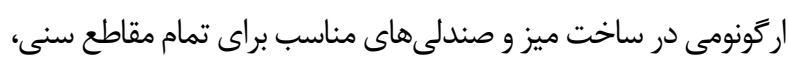

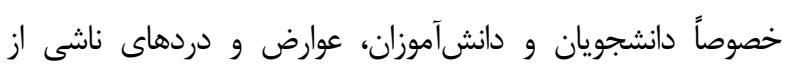

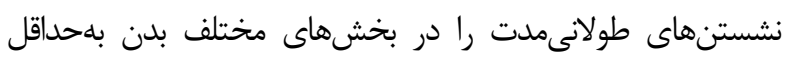

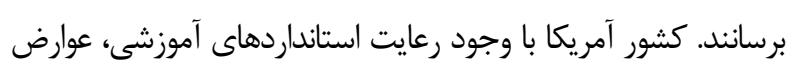

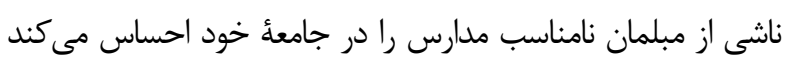

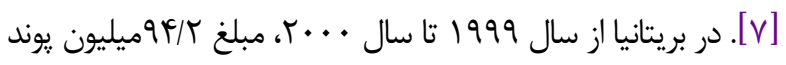

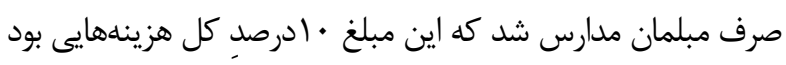

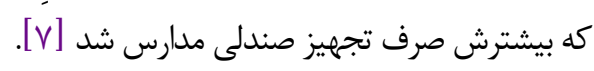

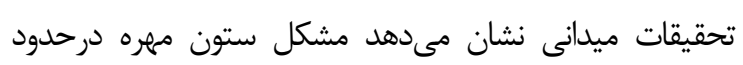

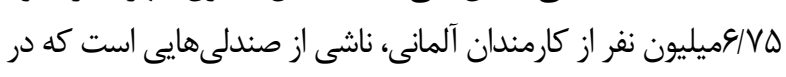

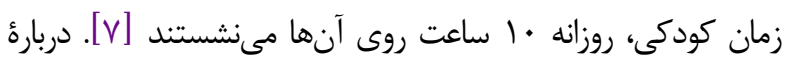

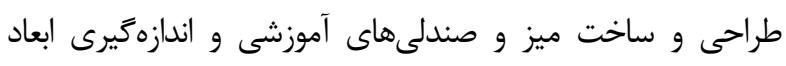

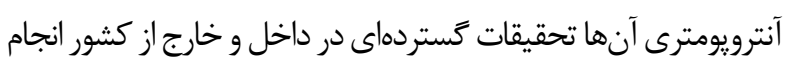

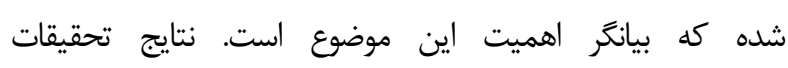
Panagiotopoulou

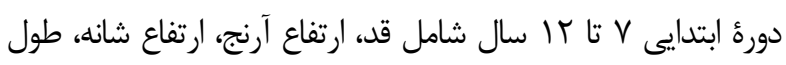

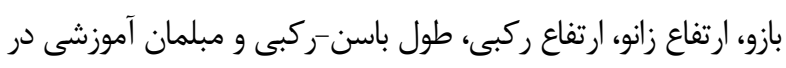


بود كه مبلمان آموزشى موجود براى تعداد زيادى از كاربران مناسب نيست [ب]. Parvez و همكاران در بررسى ميزان تطابقنداشتن اركونومى بين

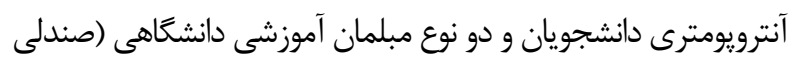

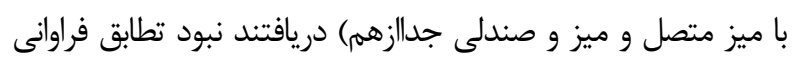

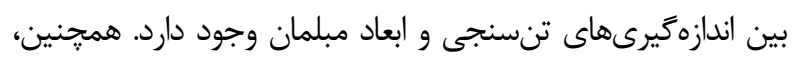

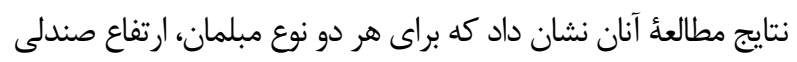

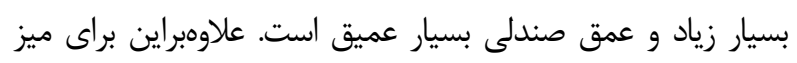

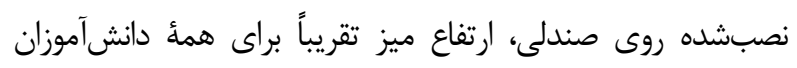

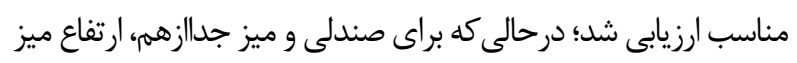

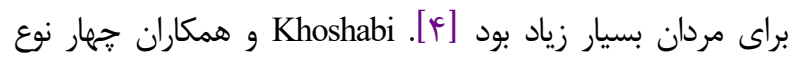

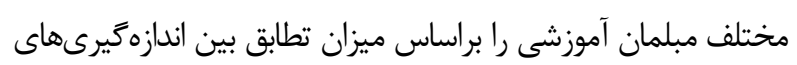

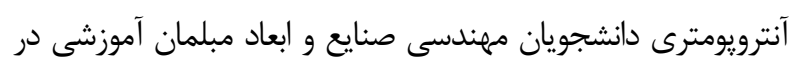

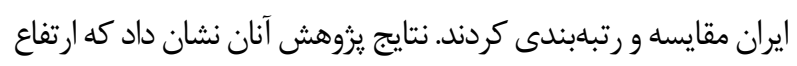

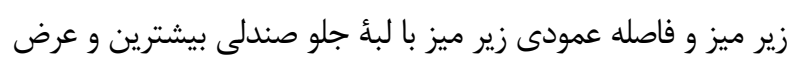

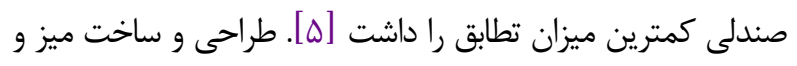

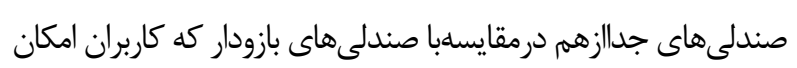

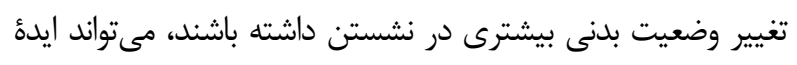

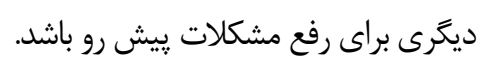

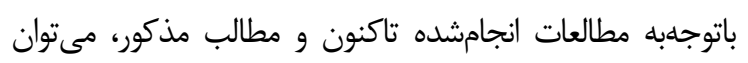

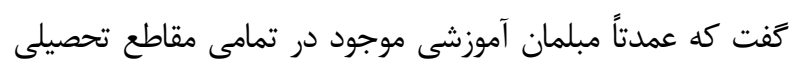

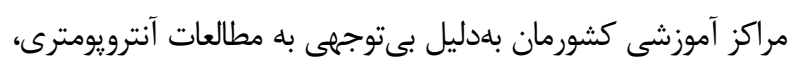

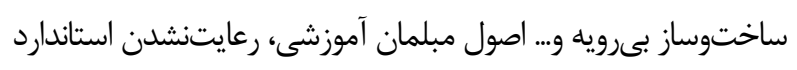

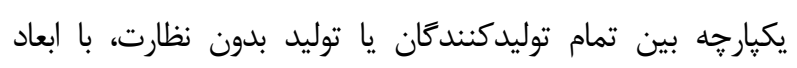

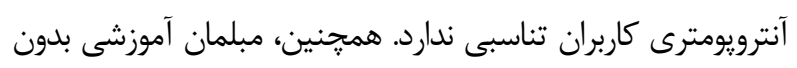

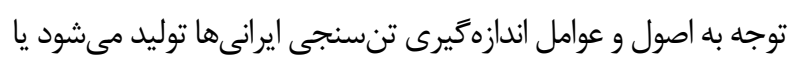

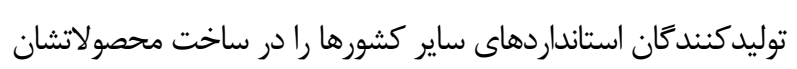

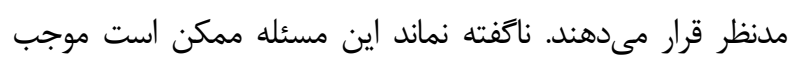

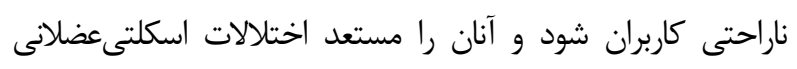

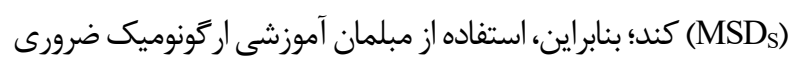

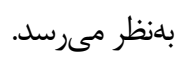
شايان ذكر است كه مشكلات ذكرشده به كشورمان محدود نيست

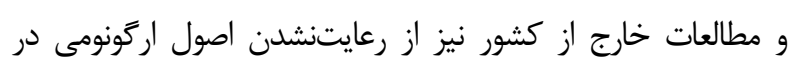

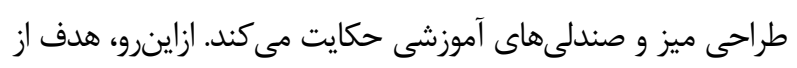

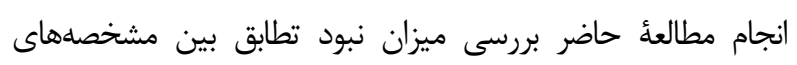

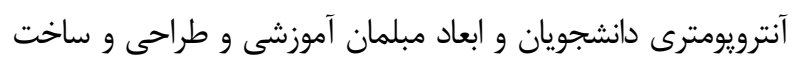

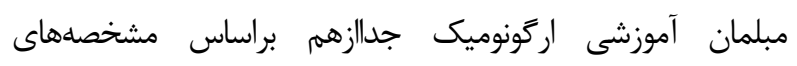

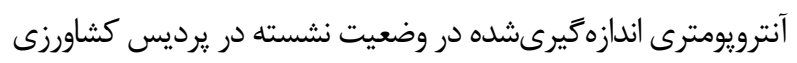

همجنين، نتايج ارزيابىهاى Heidari Moghadam و همكاران بر

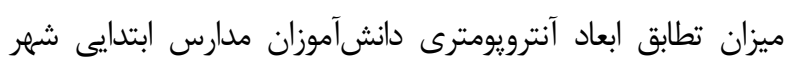

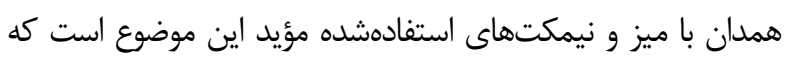

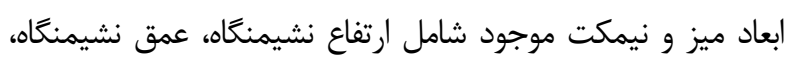

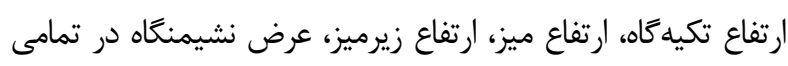

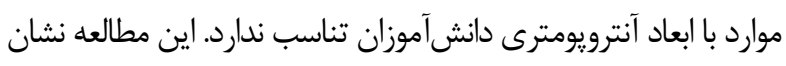

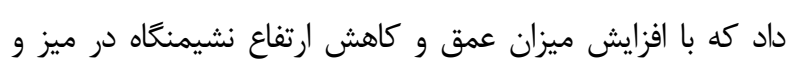

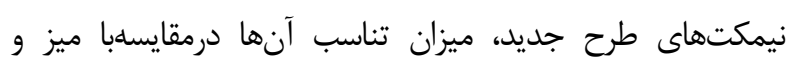

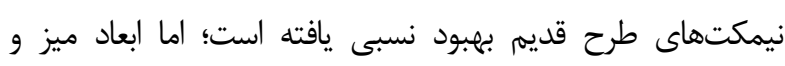

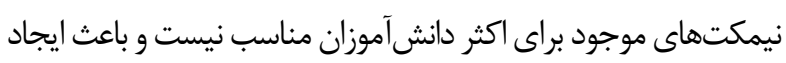

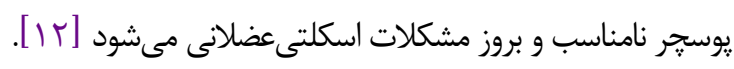

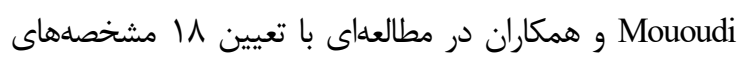

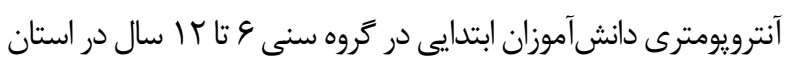

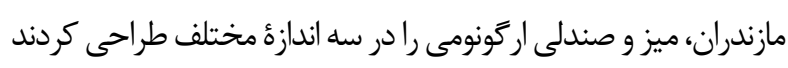

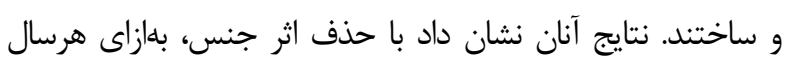

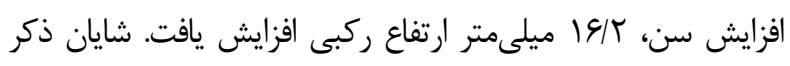

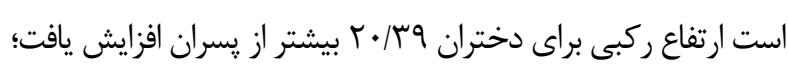

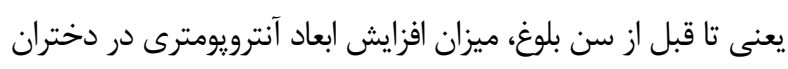

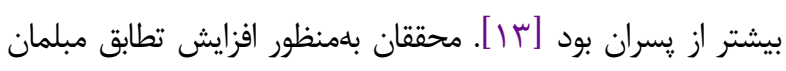

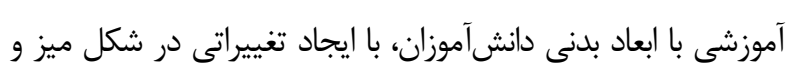

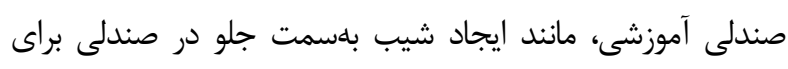

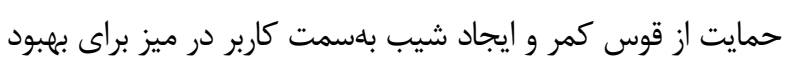

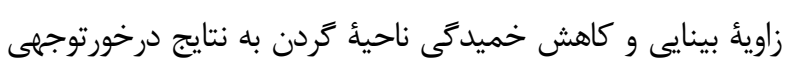

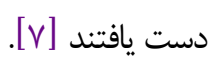
نتايج تحقيقات Rajabi Shameli و همكاران درباره ارتباط

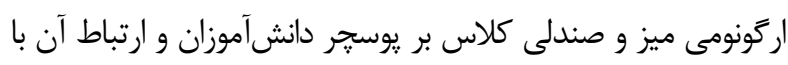
اختلالات عضلانىاسكلتى در دانشآموزان مقطع ششم ابتدايى شهر

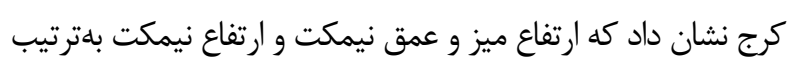

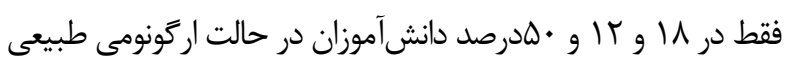

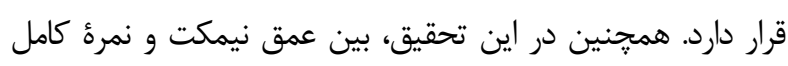

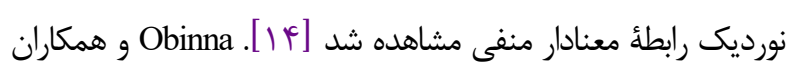

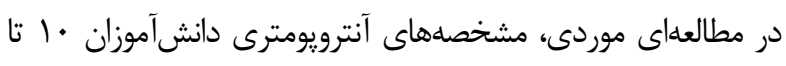

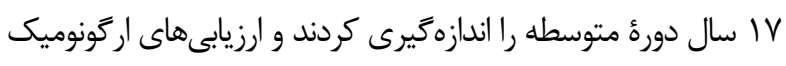

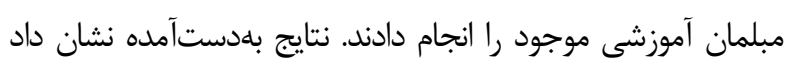

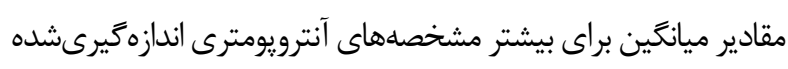

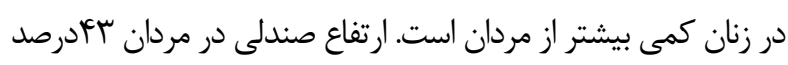

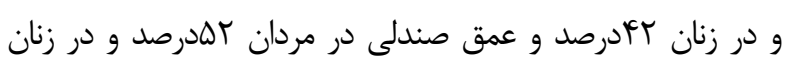
VIrV 


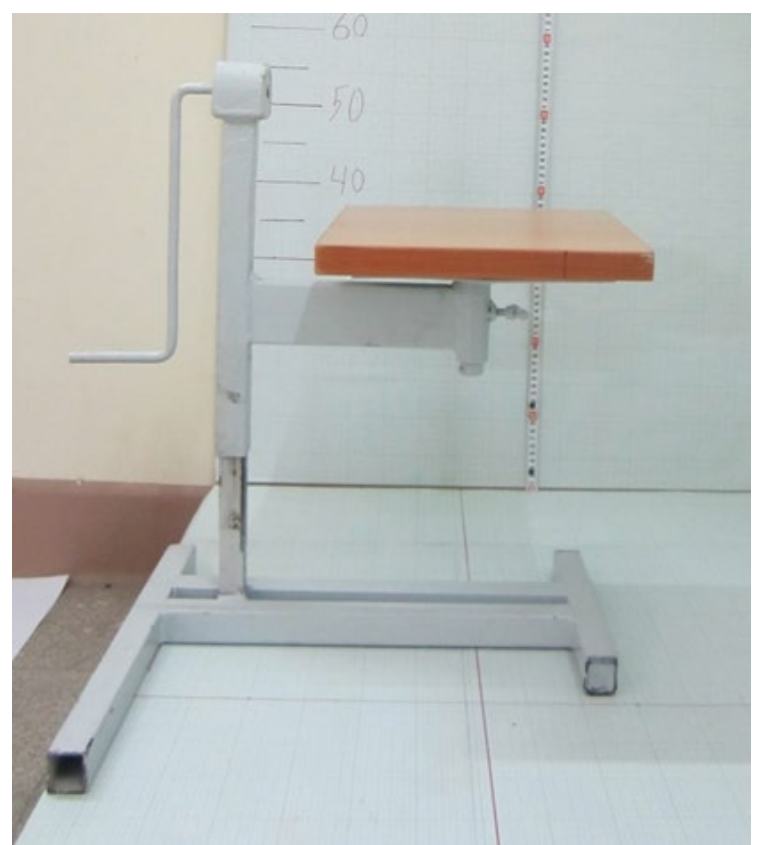

$\varphi$

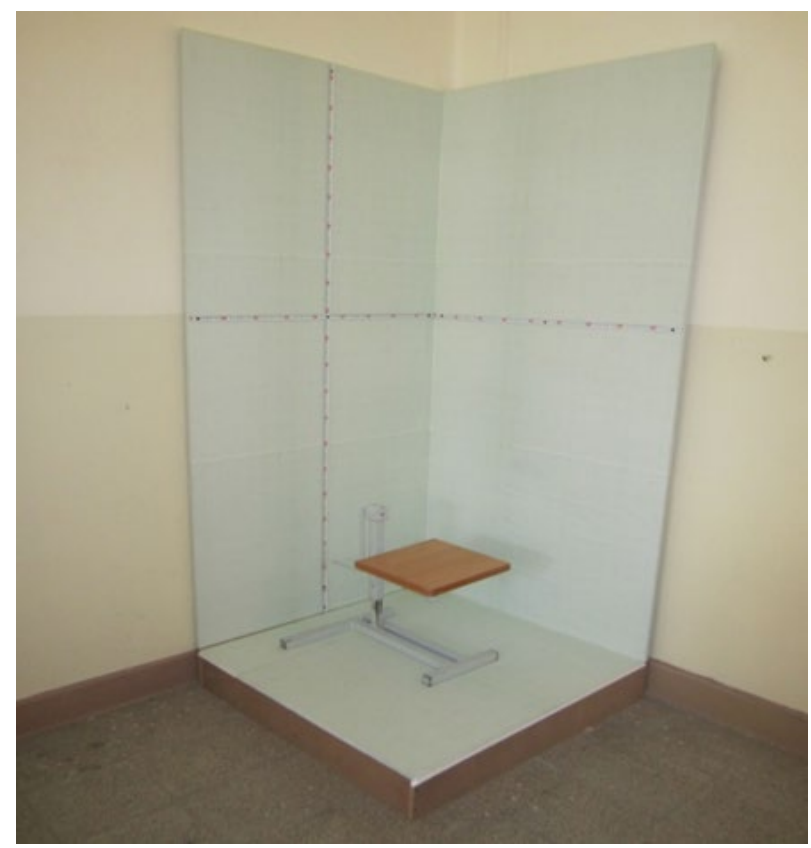

الف

شكل (: تجهيزات اندازهيرى مشخصههاى آنترويومترى الف) استاديومتر آنترويومترى، ب) صندلى آنترويومترى ب

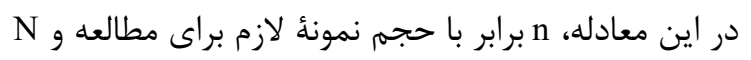

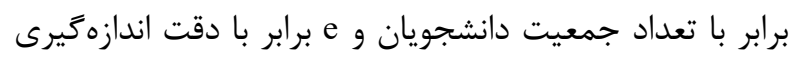

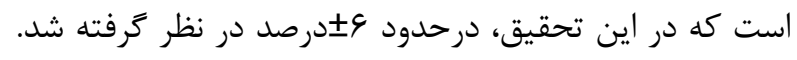

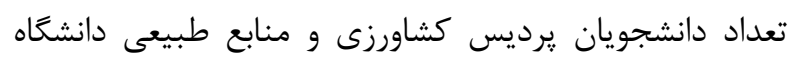

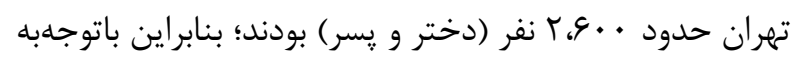

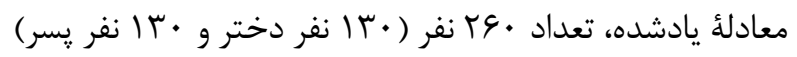

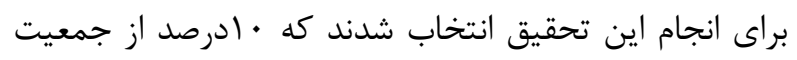

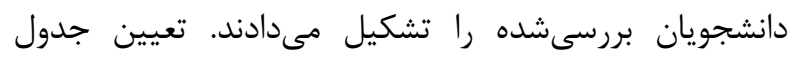

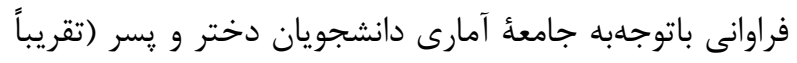

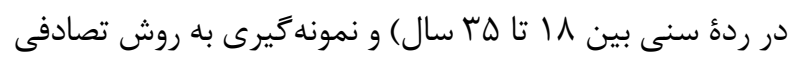

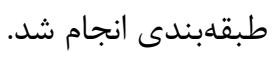

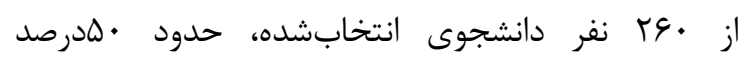

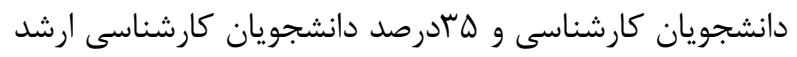

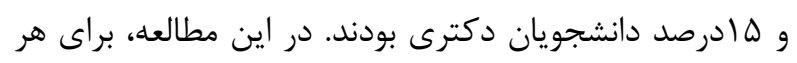

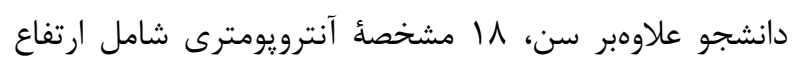

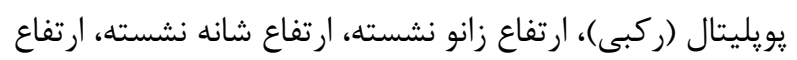

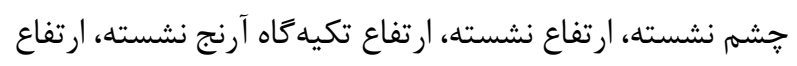

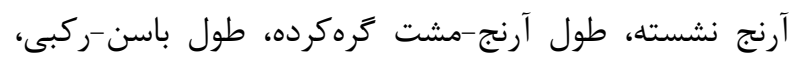

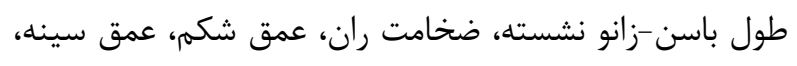

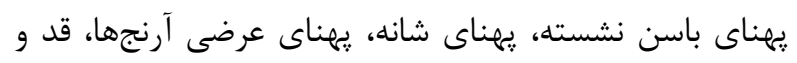

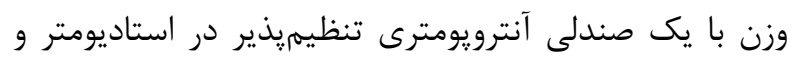

و منابع طبيعى دانشكاه تهران بود. در اين تحقيق، با هدف كاهش

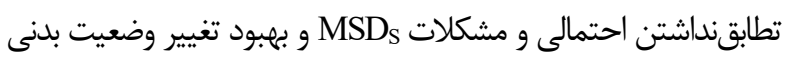

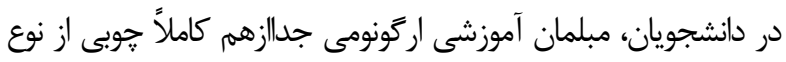

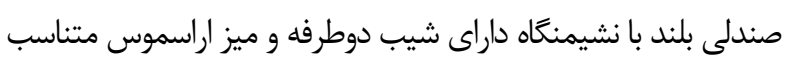

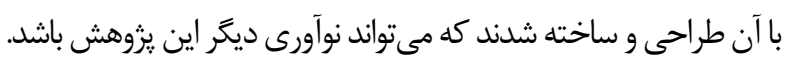

\section{روش كار}

يزوهش حاضر از نوع مقطعى بود كه بلهورت

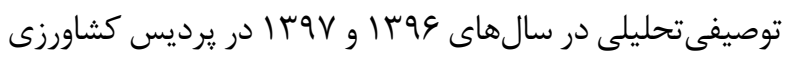

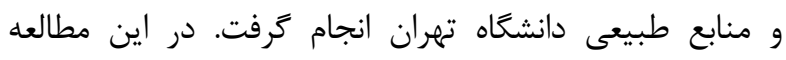

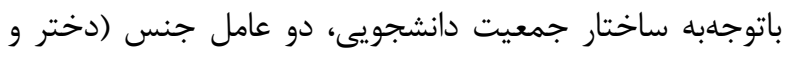

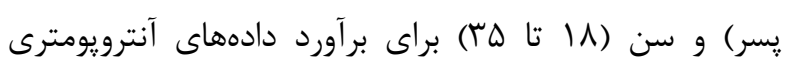
دانشجويان مدنظر قرار كرفت. براى انتخاب نمونهها از جمعيت انتراي

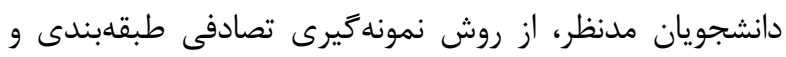

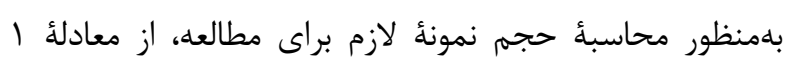
استفاده شد [ه 19 19 19]:

$$
n=\frac{N}{\left(1+N e^{2}\right)}
$$

معادلة 
دانشجويان تعيين شدند. كفتنى است كه مشاركت دانشجويان در اين تحقيق براساس اصول اخلاقى بود و مشخصههاى

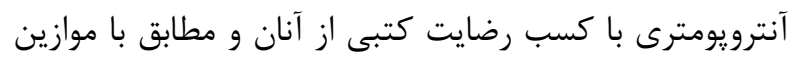

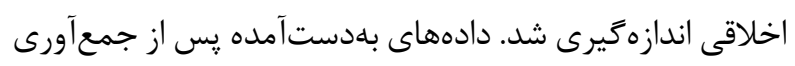

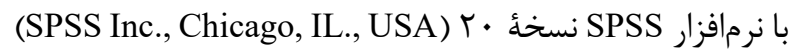

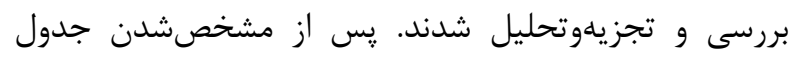

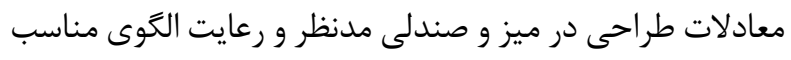

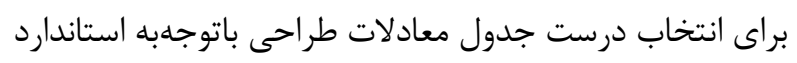

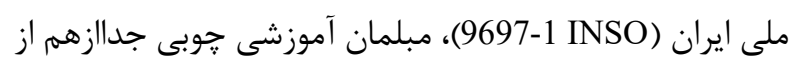

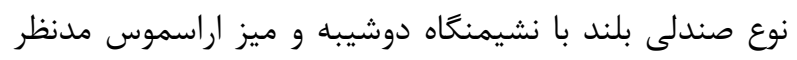
طراحى و ساخته شدند (شكل r).
ترازو اندازهيرى شد. استاديومتر بهكارففته براى اندازهخيرى

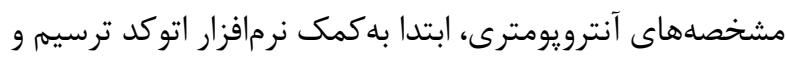

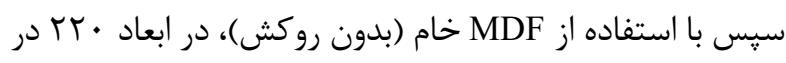

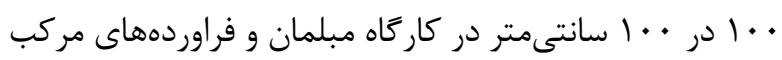

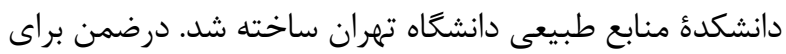

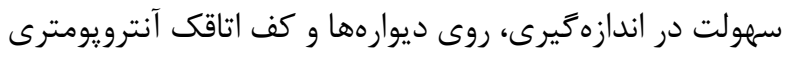

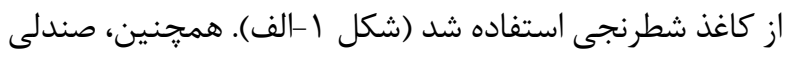

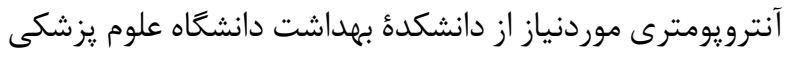

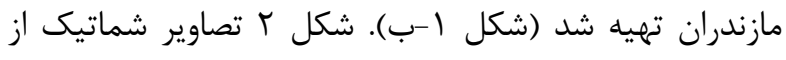

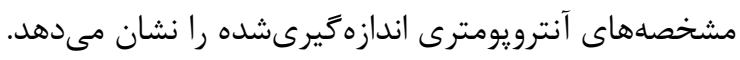

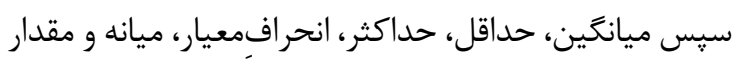

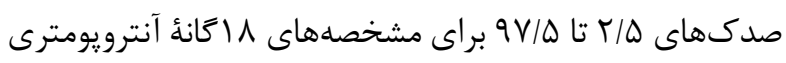

13

12

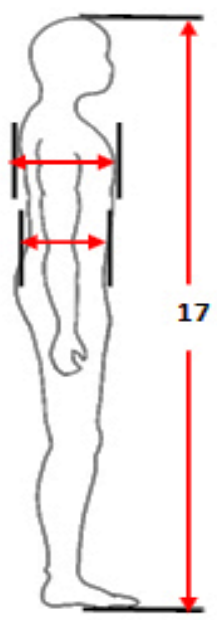

11

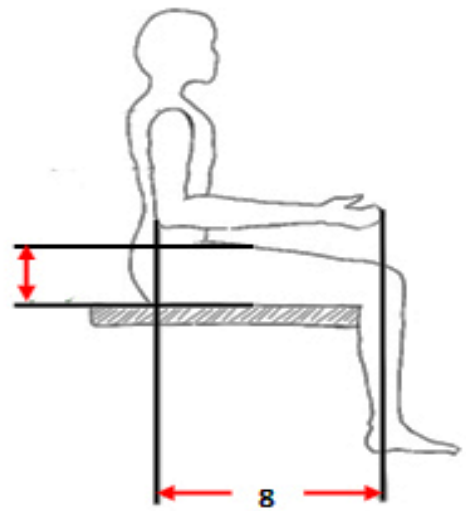

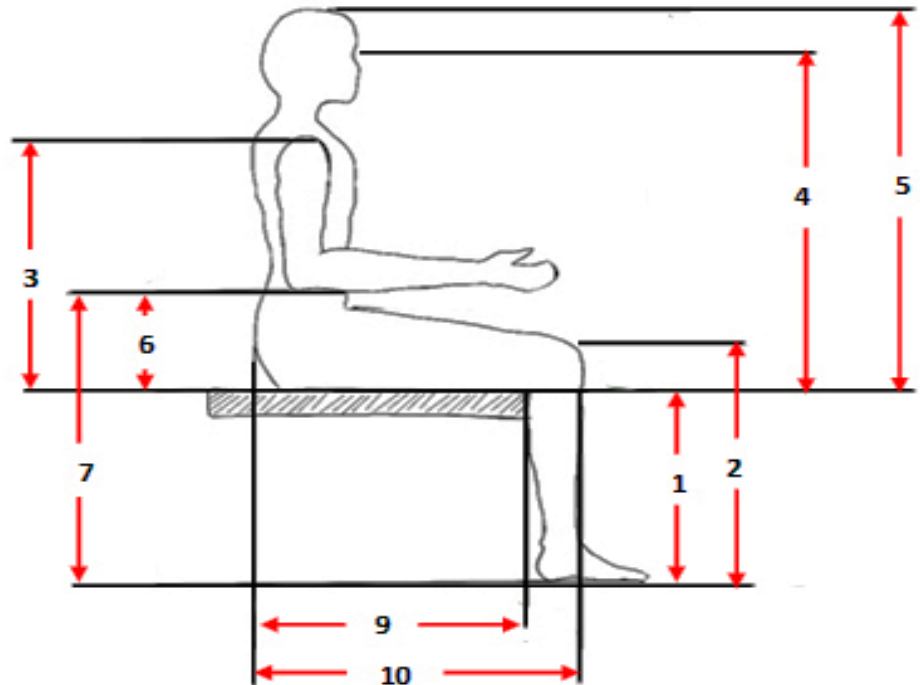

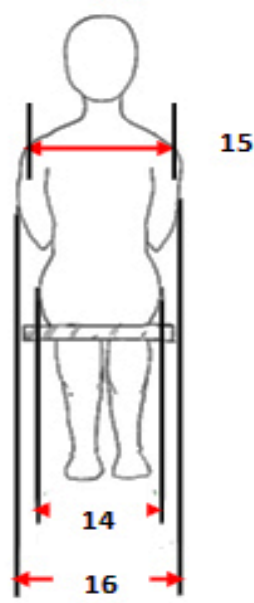

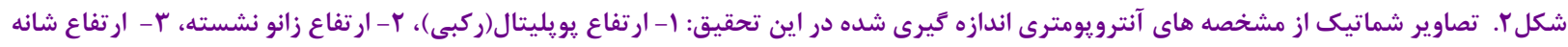

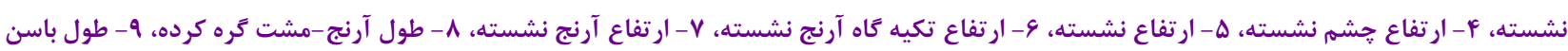

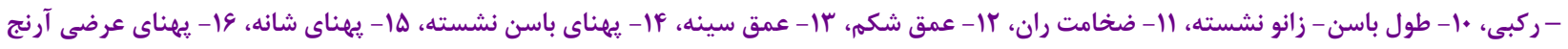
ها، IV 


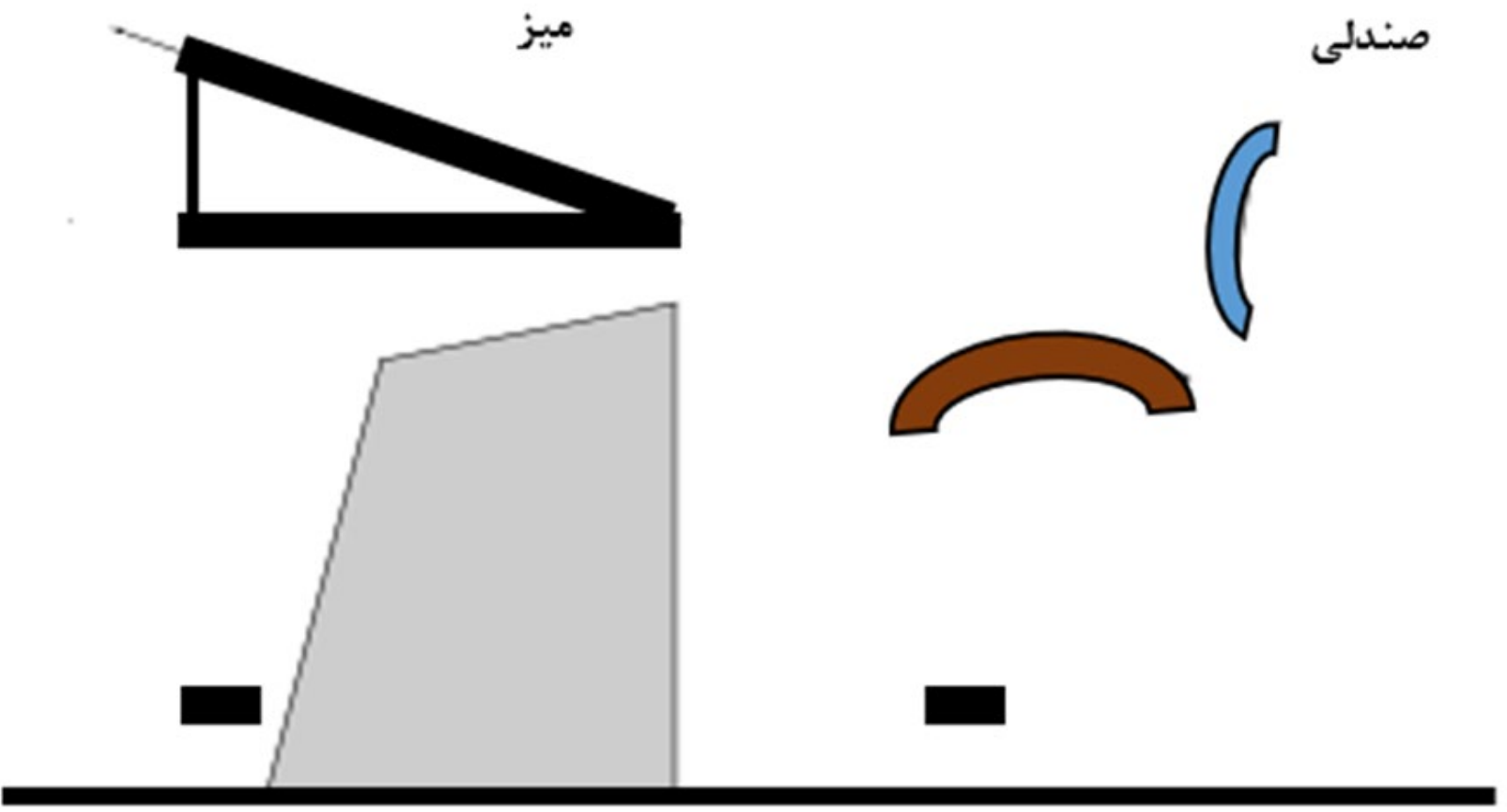

شكل - طرح مبلمان آموزشى جدا از هم جهت ساخت در اين تحقيق از نوع صندلى بلند همراه با نشيمنگًاه دو شيبه و ميز اراسموس

بافته ها

غيريارامتريك يو مانويتنى بررسى شد. نتايج بهدستآمده نشان

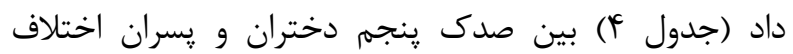

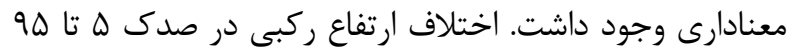

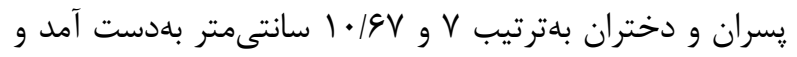

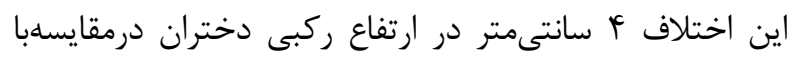

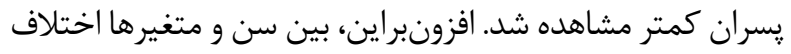

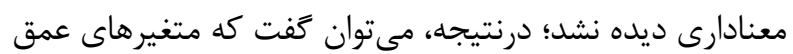

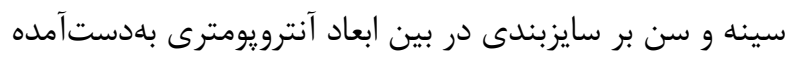
از دانشجويان تأثيرى نمى كذارد.
جداول ا تا ب مقادير حداقل، حداكثر، ميانگَين، انحرافِمعيار،

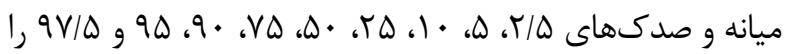

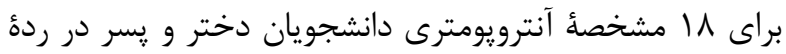

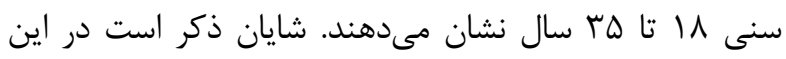
يزوهش، تمامى ابعاد اندازهيرىشده بهصورت نشسته و بدون كفش بود [IV] بعد از مشخصشدن نتايج توزيع غيرطبيعى دادهها باتوجابه

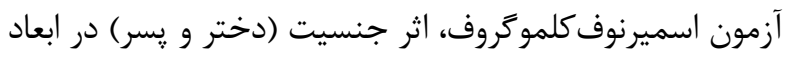

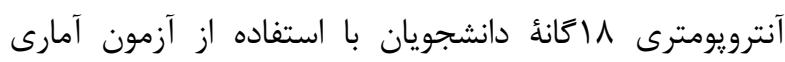

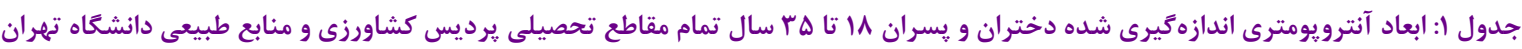

\begin{tabular}{|c|c|c|c|c|c|c|c|c|c|c|c|c|c|c|c|}
\hline \multicolumn{9}{|c|}{ صدكها } & \multirow{2}{*}{ ميانه ل } & \multirow{2}{*}{ انحراف معيار } & \multirow{2}{*}{ ميانكين } & \multirow{2}{*}{ حداكثر } & \multirow{2}{*}{ حداقل } & \multirow{2}{*}{ تعداد } & \multirow{2}{*}{ متغيرهاى آنترويومترى } \\
\hline q $/ \Delta$ & १ด & 9. & $v \Delta$ & $\Delta$. & ra & 1. & $\Delta$ & $r / \Delta$ & & & & & & & \\
\hline$\Delta \cdot$ & $p q$ & pA & pq & $\mu F / \Delta$ & $r r / \Delta$ & pl & p. & rA & FF/D & $r / \Lambda$ & $f F / f$ & $\Delta 1$ & rv & rq. & ارتفاع ركبى (cm) \\
\hline 9.10 & $\Delta q$ & $\Delta \Lambda$ & $\Delta \Delta$ & $\Delta r$ & $\kappa q / \Delta$ & $p v$ & $\varphi \& / \Delta$ & $F \Delta / \Delta$ & $\Delta r$ & $r / 9$ & $\Delta r / \Delta$ & $91 / \Delta$ & pr & rq. & ارتفاع زانو (cm) \\
\hline sq/v & 99 & 99 & $q r$ & 9. & $\Delta v$ & $\Delta \Delta$ & $\Delta r / \Delta$ & $\Delta r$ & 9. & $F / \Lambda$ & $9 \cdot / r$ & $\wedge \Delta$ & iA & rq. & ارتفاع شانه (cm) \\
\hline$\wedge \& / V$ & $\wedge \Delta$ & ^r & $\wedge$. & ve & vr & $v \cdot / 1$ & $9 \mathrm{~V} / \Delta$ & $\varphi \Delta / r$ & ve & 911 & 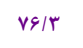 & 119 & $\Leftrightarrow q / \Delta$ & rq. & ارتفاع حشم (cm) \\
\hline $9 \mathrm{v} / \mathrm{r}$ & १९ & ap & $9 \cdot / \Delta$ & $\wedge \vee$ & $\wedge r / \Delta$ & $\Lambda \cdot / \Delta$ & $v a / \Delta$ & $v V / \Delta$ & $\Delta v$ & $\Delta / 1$ & $\wedge v$ & 1.1 & ve & rq. & ارتفاع نشسته (cm) \\
\hline r & $r$. & rq & $r q / \Delta$ & $r q / r$ & $r r / \Delta$ & $r . / \Delta$ & $19 / \Delta$ & 19 & $r \varphi / r$ & $r / 1$ & $r F / \Delta$ & rr & 11 & rq. & رتفاع تكيدكاه آرنج (cm) \\
\hline$r v / r$ & vQ & ve & $n$ & 99 & 9911 & $s \% / \Delta$ & gr & $91 / \%$ & 99 & $F / \Delta$ & $9 N / V$ & $\Lambda N / \Delta$ & $r F / \Delta$ & rq. & ارتفاع آرنج (cm) \\
\hline
\end{tabular}




\section{صدكها}

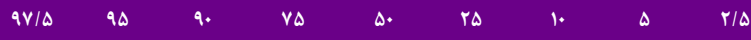

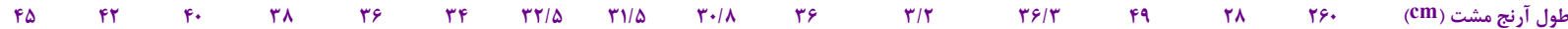

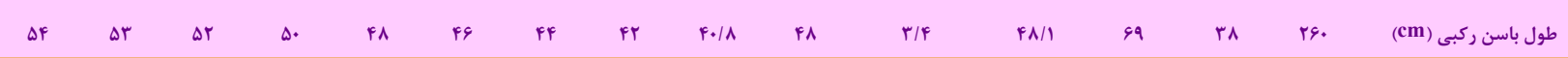

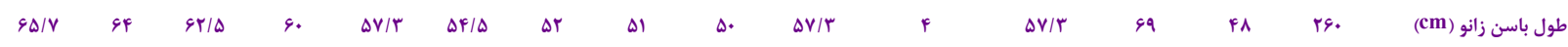

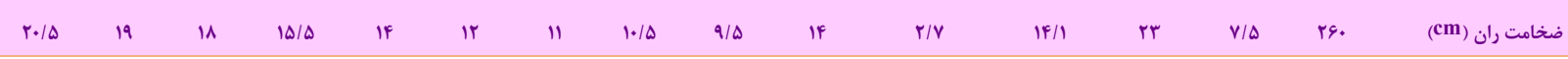

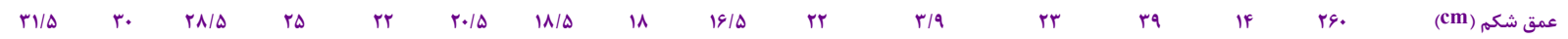

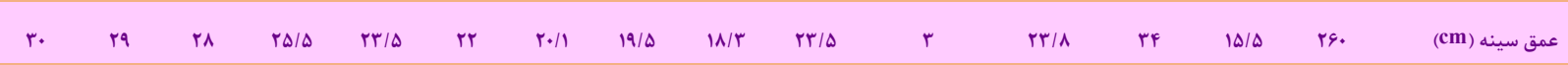

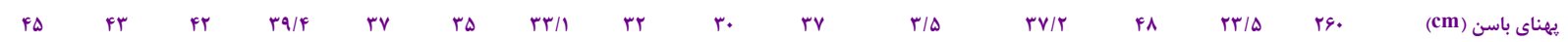

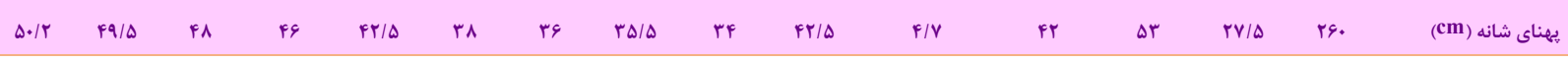

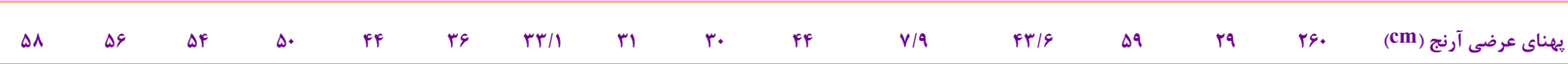

\begin{tabular}{|c|c|c|c|c|c|c|c|c|c|c|c|c|c|c|c|}
\hline 119 & $1 \wedge \Delta$ & IAT & $|V q| A$ & iv. & IET & $1 \Delta V$ & 109 & $1 \Delta r / \Delta$ & Iv. & $9 / 8$ & $199 / 9$ & 197 & וr| & rq. & قد (cm) \\
\hline $9 \Delta / \Delta$ & ar & $\wedge \wedge$ & $V \varepsilon / A$ & $9 \Delta$ & $\Delta G / T$ & $\Delta$. & rA & $F q / 0$ & $9 \Delta$ & $I F / r$ & $q V / T$ & $\pi$. & rq & rq. & وزن (Kg) \\
\hline$r / / \Delta$ & rq & $r V / q$ & rF & $r r$ & r. & 19 & 19 & 11 & rr & $r / f$ & rr/A & ro & 11 & rq. & سن \\
\hline
\end{tabular}

جدول r: ابعاد آنترويومترى اندازهيرى شده دختران 1 ا تا ها سال تمام مقاطع تحصيلى هرديس كشاورزى و منابع طبيعى دانشعاه تهران صدكها

\begin{tabular}{|c|c|c|c|c|c|c|c|c|c|c|c|c|c|c|c|}
\hline \multicolumn{9}{|c|}{ صدىها } & \multirow[b]{2}{*}{ ميانه } & \multirow[b]{2}{*}{ انحراف معيار } & \multirow[b]{2}{*}{ ميانكين } & \multirow[b]{2}{*}{ حداكثر } & \multirow[b]{2}{*}{ حداقل } & \multirow[b]{2}{*}{ تعداد } & \multirow[b]{2}{*}{ متغيرهاى آنترويومترى } \\
\hline $9 \vee / \Delta$ & $9 \Delta$ & १. & va & $\Delta$. & ro & 1. & $\Delta$ & $r / \Delta$ & & & & & & & \\
\hline$+9 / 9$ & $\& \mathcal{N} /$ & $p v / \Delta$ & $f \Delta / 1$ & fr & $+1 / \Delta$ & r. & r & $r V / r$ & rr & $r / 9$ & $r \mu / f$ & $\Delta$. & rr & ir. & ارتفاع ركبى (cm) \\
\hline$\Delta \Delta / f$ & $\Delta \Delta$ & $\Delta F$ & $\Delta 1 / 1$ & $+9 / \Delta$ & $r V / \Delta$ & $+9 / \Delta$ & $F \Delta / \Delta$ & $F+/ r$ & Fqu & $r / \Lambda$ & $\uparrow q / \%$ & $\Delta 9$ & fr & ir. & ارتفاع زانو (cm) \\
\hline 49 & $99 / 0$ & $9 \pi$ & 4. & $\Delta V / \Delta$ & $\Delta \Delta / 9$ & $\Delta r / \varphi$ & $\Delta$. & $\Delta \cdot / q$ & $\Delta V / \Delta$ & $r / 9$ & $\Delta N / 1$ & v. & $\ll q / \Delta$ & ir. & ارتفاع شانه (cm) \\
\hline$\Lambda T / \Delta$ & $1 \mathrm{~N} / \mathrm{V}$ & vq & vo & $V r / s$ & vi & $9 N / 1$ & $9 \Delta / \Delta$ & $41 / V$ & $V / \Delta$ & $F / F$ & $V T / T$ & $\Delta F$ & $\Delta q / \Delta$ & ir. & ارتفاع حشم (cm) \\
\hline $9 \% / V$ & $91 / V$ & 9. & $\wedge \varepsilon$ & $\Lambda F$ & $11 / \Delta$ & $v 9 / \Delta$ & VW/S & $\Delta V / G$ & $\Delta f$ & $+/ 1$ & $\Delta f$ & १ง & ve & $i r$. & ارتفاع نشسته (cm) \\
\hline rq/q & rs & $r V / \Delta$ & $r \Delta / \Delta$ & re & rt & $r \cdot / \Delta$ & $19 / \Delta$ & IN/9 & rf & $r / \Lambda$ & $r r / \Lambda$ & rr & $\Lambda F / \Delta$ & ir. & ارتفاع تكيدكاه آرنج (cm) \\
\hline$v \Delta / 1$ & $V \pi / V$ & vr & $99 / 0$ & $9 V / \Delta$ & $44 / 9$ & GT/Q & $91 / \pi$ & $\Delta Q / r$ & $9 V / \Delta$ & F/9 & $4 V$ & ve & $\kappa r / \Delta$ & ir. & ارتفاع آرنج (cm) \\
\hline $4 \cdot / v$ & rq & rN/q & $r \Delta / \Delta$ & re & rr & $r 1 / \theta$ & $r \cdot / \Lambda$ & rq/द & re & $r / \Delta$ & $r F / \Delta$ & fr & rA & ir. & طول آرنج مشت (cm) \\
\hline$\Delta r / \Delta$ & $\Delta T / V$ & $\Delta 1 / \Delta$ & $\Delta$. & fr/a & $f \Delta / \Delta$ & Ff & er & $f / / r$ & $v \leftarrow / \Delta$ & $r / 1$ & $F V / \Delta$ & $\Delta \Delta$ & $r q / \Delta$ & ir. & طول باسن ركبى (cm) \\
\hline st & 4. & $\Delta 9$ & $\Delta v$ & $\Delta F / \Delta$ & $\Delta T / \Delta$ & $\Delta 1$ & $\Delta$. & $+9 / 1$ & $\Delta F / \Delta$ & $+/ 1$ & $\Delta F / \Lambda$ & sr & rA & ir. & طول باسن زانو (cm) \\
\hline $19 / \mathrm{V}$ & 19 & 11 & $|f /|$ & $1 T / \Delta$ & 11 & $1 \cdot / 0$ & $9 / \Delta$ & 9 & $\mid T / \Delta$ & $r / \Lambda$ & $|r /|$ & rr & $V / \Delta$ & ir. & ضخامت ران (cm) \\
\hline$r \cdot / \Delta$ & rq/V & rV & rf & $r$ & $19 / \Delta$ & 11 & 1919 & $\mid F / 9$ & rI & r/v & $r / / \Lambda$ & rr & if & ir. & عمق شكم (cm) \\
\hline$r \cdot / v$ & $r$. & rA & $r \Delta / \Delta$ & re & $r \mid / F$ & $r \cdot$ & $N / \Delta$ & iv & $r \Lambda$ & $r / r$ & $r \pi / 4$ & $r f$ & $10 / \Delta$ & ir. & عمق سينه (cm) \\
\hline Fr/V & $F T / \Delta$ & $F \cdot / \Delta$ & $r N / \Delta$ & re & rf & rr & $r \cdot / \Lambda$ & $r q / \Delta$ & re & $r / \Delta$ & $r g / f$ & Fa & $r r / \Delta$ & ir. & يِهناى باسن (cm) \\
\hline Fo & $+\% / \Delta$ & rr & r. & ru & $r e / 0$ & $r \Delta / \Delta$ & $r \in / T$ & rr/g & $r \wedge$ & $r / \Lambda$ & $r N / f$ & 48 & $r r / \Delta$ & $i r$. & بِيهناى شانه (cm) \\
\hline$\Delta$. & FN/D & $\$ 9 / \Delta$ & +1 & re/r & $r F / F$ & $r \mid / s$ & r. & $r q / \Delta$ & reाr & $\Delta / r$ & $r V / v$ & $\Delta 1$ & rq & ir. & يجناى عرضى آرنج (cm) \\
\hline ivr & IVT/V & iv. & $19 V / 8$ & 195 & $10 N / 9$ & 108 & $10 \% / 9$ & $10 \cdot 19$ & IST & s/4 & $\mid 9 T / r$ & ivr & $|r|$ & $i r$. & قد (cm) \\
\hline $11 / V$ & $\wedge$. & vr & $9+11$ & $\Delta \wedge$ & $\Delta T$ & +1 & $+9 / 9$ & $F+/ T$ & $\Delta \wedge$ & $9 / 1$ & $\Delta N / 9$ & af & rq & ir. & وزن (Kg) \\
\hline$r r / \Delta$ & $r \cdot / \Delta$ & $r \Lambda$ & To & rt & r. & 19 & 19 & INT & $\pi$ & $r / v$ & $r T / 1$ & ג & 11 & ir. & سن \\
\hline
\end{tabular}




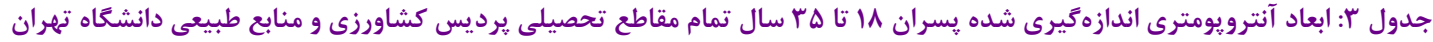

\begin{tabular}{|c|c|c|c|c|c|c|c|c|c|c|c|c|c|c|c|}
\hline \multirow{2}{*}{$9 \vee / \Delta$} & \multicolumn{8}{|c|}{ صدكها } & \multirow{2}{*}{ ميانه } & \multirow{2}{*}{ انحراف معيار } & \multirow{2}{*}{ ميانكين } & \multirow{2}{*}{ حداكثر } & \multirow{2}{*}{ حداقل } & \multirow{2}{*}{ تعداد } & \multirow{2}{*}{ متغير هاى آنترويومترى } \\
\hline & $१ \Delta$ & q. & $V \Delta$ & $\Delta$. & ra & 1. & $\Delta$ & $r / \Delta$ & & & & & & & \\
\hline$\Delta \cdot$ & $4 q$ & $4 q$ & pv & $F_{\Delta}$ & fr & $F Y / Q$ & kr & $r \cdot r$ & $i_{\Delta}$ & $r / r$ & $f \Delta / r$ & $\Delta 1$ & r. & $i r$. & ارتفاع ركبى (cm) \\
\hline 91 & $4 \cdot 10$ & $\Delta 9$ & $\Delta V$ & $\Delta \Delta$ & $\Delta F$ & $\Delta r$ & $\Delta r$ & DI & $\Delta \Delta$ & $r / \Delta$ & $\Delta \Delta / f$ & $91 / \Delta$ & \&q & $1 r$. & ارتفاع زانو (cm) \\
\hline$V T / \Delta$ & $99 / 0$ & $9 V$ & 90 & ar & 4. & $\Delta N / 1$ & $\Delta \Delta / \Delta$ & $\Delta F / G$ & Gr & $4 / 9$ & $9 \% / \Delta$ & $\wedge \Delta$ & is & $1 r$. & ارتفاع شانه (cm) \\
\hline$M N / F$ & $\Lambda 9 / V$ & $\wedge \Delta$ & $\wedge 1 / \Delta$ & $\mathrm{V} / / \mathrm{r}$ & ve & $V \psi / \Delta$ & $V r / \Delta$ & $V Y / I$ & V৭/r & $r / 9$ & va/r & 19 & n & $i r$. & ارتفاع حشم (cm) \\
\hline $99 / \uparrow$ & $9 v / r$ & १९ & $9 \pi$ & 9. & $\wedge V$ & $\Lambda \Delta / \Delta$ & $\wedge f$ & $\Lambda \cdot / 1$ & 9. & $r / r$ & $9 \cdot / 1$ & 1.1 & vı & $i r$. & ارتفاع نشسته (cm) \\
\hline$r M / V$ & $r \cdot / r$ & $r q / \Delta$ & r^ & rQ & $r r$ & rl & $19 / 1$ & 19 & rQ & $r / r$ & $r \Delta / r$ & rr & 11 & ir. & ارتفاع تكيه كاه آرنج (cm) \\
\hline vq & $V V / T$ & $v \Delta$ & vr & $\vee \cdot$ & $s \mathrm{~V} / \mathrm{Q}$ & $9 \Delta / 9$ & $9 \Delta$ & $s 4$ & $v \cdot$ & $r / V$ & $v \cdot / f$ & $\Lambda 1 / \Delta$ & st & $1 r$ & ارتفاع آرنج (cm) \\
\hline f\& & $f \Delta$ & fr & rq & $r V / Q$ & re & $r \Delta$ & ro & rr/s & $V r / Q$ & $r / 9$ & $r N / 1$ & $4 q$ & r & $1 \pi$ & طول آرنج مشت (cm) \\
\hline$\Delta \varphi / V$ & $\Delta r / \Delta$ & $\Delta r$ & $\Delta \cdot$ & $F N / Q$ & ev & is & $\mid+1 / 9$ & $4 \cdot / 1$ & $Y N / Q$ & $r / V$ & YN/S & 99 & rی & $1 r$ & طول باسن ركبى (cm) \\
\hline $9 V / 9$ & $9 \Delta / V$ & $q 4$ & st & $\Delta 9 / 1$ & $\Delta \wedge$ & $\Delta v$ & $\Delta \varphi$ & $\Delta F / T$ & $\Delta 9 / \wedge$ & $r / 1$ & $\Delta 9 / 9$ & 99 & $\Delta r$ & $1 r$ & طول باسن زانو (cm) \\
\hline$r \mid / r$ & $19 / 0$ & 11 & 19 & $\mid f / \Delta$ & $1 r / \Delta$ & $1 T / 9$ & ir & $11 / 1$ & $\mid f / \Delta$ & r.r & 10 & rr & 11 & $i r$. & ضخامت ران (cm) \\
\hline$r F / l$ & $r \cdot / \Delta$ & rq & re & re & $r I / F$ & r. & $19 / \Delta$ & $19 / 1$ & re & $r / V$ & TF/T & rq & 11 & ir. & عمق شكم (cm) \\
\hline rq/9 & rq & Tr & $r Q / 1$ & $r+/ \Lambda$ & rt & $r_{1}$ & $19 / 0$ & 19 & $r$ r/A & $T / V$ & $r r / q$ & r & 11 & $i r$ & عمق سينه (cm) \\
\hline is & $f \Delta$ & fr & $f \cdot$ & $r V / \Lambda$ & re & $r F / \Delta$ & r & $r i / r$ & rv/A & $r / f$ & rی & \&A & $\Delta S / \Delta$ & $\pi$ & يهناى باسن (cm) \\
\hline$\Delta 1$ & $\Delta \cdot / r$ & $49 / \Delta$ & FV/G & $f \Delta / r$ & ff & fr & $41 / r$ & $4 \cdot 19$ & $r \Delta / r$ & $r / r$ & $f \Delta / 9$ & $\Delta r$ & $r V / \Delta$ & $1 r$. & يهناى شانه (cm) \\
\hline$\Delta 9$ & $\Delta \wedge$ & $\Delta \varphi$ & $\Delta r$ & $49 / 8$ & \&\& & fr & $4 \cdot 1 /$ & $r V / f$ & $r q / \Delta$ & $\Delta / f$ & $q q / \uparrow$ & $\Delta q$ & $r \cdot$ & $1 r$ & لِهناى عرضى آرنج (cm) \\
\hline 19. & 119 & $1 \wedge \Delta$ & $|1|$ & IVe & ivr & iv. & $19 \mathrm{~V} / 9$ & $199 / 4$ & IVe & $\Delta / 9$ & IVV & 194 & 194 & $i r$ & قد (cm) \\
\hline $99 / V$ & $9 \Delta / \Delta$ & ar & $\Lambda r / r$ & vo & 99 & 4. & $\Delta V / /$ & $\Delta \Delta$ & $V \Delta$ & $|r /|$ & $V Q / 9$ & $1 r$. & $4 q$ & ir. & وزن (Kg) \\
\hline$r q / V$ & rq & $r 9 / 9$ & tF & rt & r. & 19 & 19 & 11 & rt & $r / r$ & $r t / F$ & $r \Delta$ & 11 & $1 r$. & سن \\
\hline
\end{tabular}

جدول لأ نتايج آزمون آمارى يو مان -ويتنى براى مقايسه متغيرها در جنسيت (دختر و يسر)

\begin{tabular}{|c|c|c|c|c|c|}
\hline سطح معنى دارى & انحراف معيار & ميانگين & تعداد & جنسيت & متغير \\
\hline \multirow{2}{*}{$<\cdot 1 \cdot \cdot 1$} & $T / T V$ & $F \Delta / T 1$ & M. & 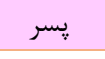 & \multirow{2}{*}{ ارتفاع ركبى(cm) } \\
\hline & $r / q$. & אוץ & M. & دختر & \\
\hline \multirow{2}{*}{$<\cdot 1 \cdot \cdot 1$} & $r / q q$ & $\Delta \omega / T G$ & $\pi$ & يسر & \multirow{2}{*}{ ارتفاع زانو(cm) } \\
\hline & GIAV & fq/q & M. & دختر & \\
\hline \multirow{2}{*}{$<\cdot 1 \cdot \cdots 1$} & $F / Q \Lambda$ & $q r / 4 q$ & $\pi$ & يسر & \multirow{2}{*}{ ارتفاع شانه(cm) } \\
\hline & r/Aq & $\Delta N / 11$ & $\pi$ & دختر & \\
\hline \multirow{2}{*}{$<\cdot 1 \cdots 1$} & ఎ/^६ & マq/TV & Ir. & 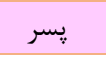 & \multirow{2}{*}{ ارتفاع جشم(cm) } \\
\hline & F/Fr & VT/lg & Ir. & دختر & \\
\hline \multirow{2}{*}{$<\cdot 1 \cdot \cdot 1$} & F/TF & $9 \cdot 1 \cdot 9$ & Ir. & يسر & \multirow{2}{*}{ ارتفاع نشسته(cm) } \\
\hline & $\boldsymbol{F} / \cdot \mathrm{V}$ & $\Lambda F / \cdot 1$ & r. & دختر & \\
\hline \multirow{2}{*}{$<\cdot 1 \cdot \cdot 1$} & $r / 19$ & $r \Delta / 19$ & Ir. & يسر & \multirow{2}{*}{ ارتفاع تكيهًَاه آرنج(cm) } \\
\hline & $r / V \Delta$ & rm/A. & $\pi$ & دختر & \\
\hline
\end{tabular}




\begin{tabular}{|c|c|c|c|c|c|}
\hline سطح معنى دارى & انحراف معيار & ميانَّين & تعداد & جنسيت & متغير \\
\hline \multirow{2}{*}{$<\cdot \mid \cdot \cdot 1$} & $r / 9 V$ & $V \cdot / r \Lambda$ & $1 r$. & 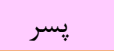 & \multirow{2}{*}{ ارتفاع آرنج(cm) } \\
\hline & f/gY & $9 V$ & $1 r$. & دختر & \\
\hline \multirow{2}{*}{$<\cdot 1 \cdot \cdot 1$} & T/AD & $r N / \cdot G$ & $1 r$. & 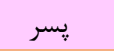 & \multirow{2}{*}{ طول آرنج مشت كرده(cm) } \\
\hline & T/QT & $m p / q q$ & $1 r \cdot$ & دختر & \\
\hline \multirow{2}{*}{$<\cdot / \cdot \cdot v$} & r/VT & $F N / D S$ & $1 r \cdot$ & يسر & \multirow{2}{*}{ طول باسن ركبى(cm) } \\
\hline & $r / \cdot \varphi$ & FV/DT & $1 r \cdot$ & دختر & \\
\hline \multirow{2}{*}{$<\cdot 1 \cdot \cdot 1$} & $r / \cdot V$ & $\Delta 9 / 9$. & $1 r \cdot$ & 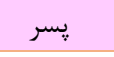 & \multirow{2}{*}{ طول باسن زانو(cm) } \\
\hline & $r / \cdot 9$ & $\Delta F / V \Lambda$ & $1 r \cdot$ & دختر & \\
\hline \multirow{2}{*}{$<\cdot / \cdot \cdot 1$} & r/Tq & $|\omega| \cdot F$ & $1 r$ & 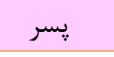 & \multirow{2}{*}{ ضخامت ران(cm) } \\
\hline & $r|\Lambda|$ & $|r /|$ & $1 r \cdot$ & دختر & \\
\hline \multirow{2}{*}{$<\cdot \mid \cdot \cdot 1$} & r/9६ & TF/YF & $1 r \cdot$ & 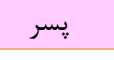 & \multirow{2}{*}{ عمق شكم(cm) } \\
\hline & $r / V I$ & rI/A. & $\pi$ & دختر & \\
\hline \multirow{2}{*}{$. / 1 V \mid$} & $r / 9 \Lambda$ & $r r / q F$ & $1 r$ & 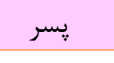 & \multirow{2}{*}{ عمق سينه(cm) } \\
\hline & $r / T V$ & $r / \Delta \Delta$ & $\pi$ & دختر & \\
\hline \multirow{2}{*}{$<\cdot 1 \cdot \cdots 1$} & $r / \mu$. & rV/ą & $1 r \cdot$ & 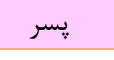 & \multirow{2}{*}{ يهناى باسن(cm) } \\
\hline & $r / F \wedge$ & $r g / 4$. & $\mu$. & دختر & \\
\hline \multirow{2}{*}{$<\cdot 1 \cdot .1$} & $r / 19$ & $F \Delta / \Delta \varphi$ & $1 r \cdot$ & 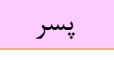 & \multirow{2}{*}{ يهناى شانه(cm) } \\
\hline & T/AF & TN/FF & 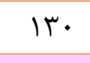 & دختر & \\
\hline \multirow{2}{*}{$<\cdot 1 \cdot \cdots 1$} & $\Delta / T \Lambda$ & $p q / r q$ & $1 \%$. & 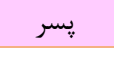 & \multirow{2}{*}{ يهناى عرضى آرنج(cm) } \\
\hline & $\Delta / \Gamma$. & $r V / V$. & $1 r \cdot$ & دختر & \\
\hline \multirow{2}{*}{$<\cdot 1 \cdot \cdot 1$} & Q/qF & $\mid V \vee V / \cdot 1$ & $1 \pi \cdot$ & 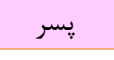 & \multirow{2}{*}{ قد(cm) } \\
\hline & $g / \Gamma \wedge$ & $19 T / K 9$ & $1 r$ & دختر & \\
\hline \multirow{2}{*}{$<\cdot 1 \cdot .1$} & $\mid r / \cdot \Delta$ & $V \Delta / \Delta \Delta$ & $1 r$. & 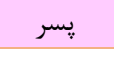 & \multirow{2}{*}{ وزن(Kg) } \\
\hline & $9 / V \vee$ & $\Delta \Lambda / \Lambda \vee$ & 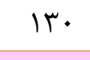 & دختر & \\
\hline \multirow{2}{*}{.$/ 1 F \wedge$} & ए/ब & Tr/ET & $1 \pi$. & يسر & \multirow{2}{*}{ سن } \\
\hline & $r / \Delta \varphi$ & $r r / \cdot q$ & r & دختر & \\
\hline
\end{tabular}

با آن مطابق با استاندارد ملى ايران (9697-1 INSO) در شكل F

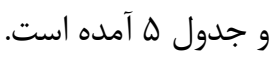
باتوجهبه جدول معادلات طراحى بهدستآمده از دانشجويان

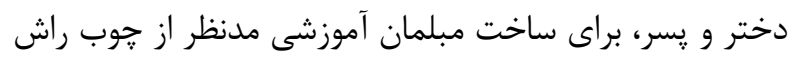

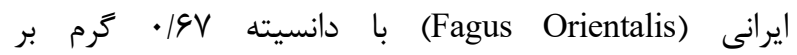
سانتىمترمكعب و رطوبت rادراني

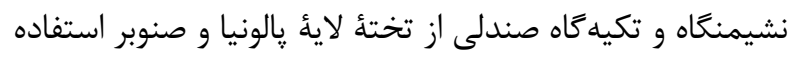

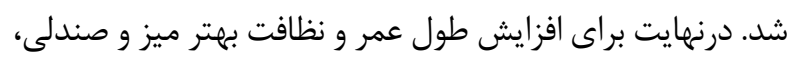
يوشش رنكى سيلر و نيم يلىاستر به كار رفت. فرايند ساخت اين

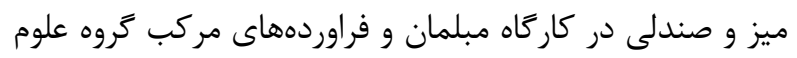
و صنايع جوب و كاغذ دانشعاه تهران و كاركاه درودگرى مرك مركز

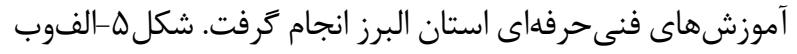
ميز و صندلى اركونومى طراحى و ساختهشده از جوب يس إنس از
طراحى و ساخت ميز و صندلى اركونومى براساس مشخصههاى آنترويومترى

يس از بررسى اثر جنسيت و مشخصشدن وجود اختلاف انتروي

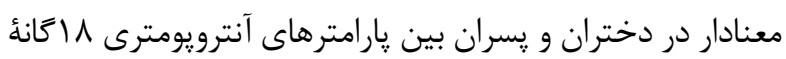

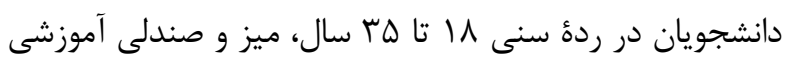

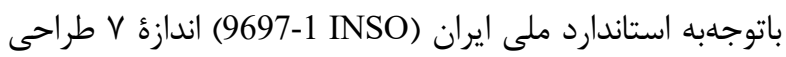

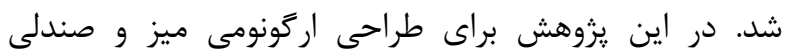

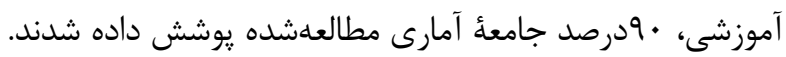

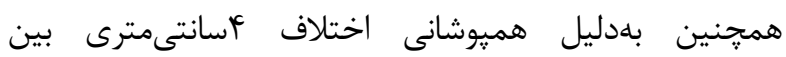

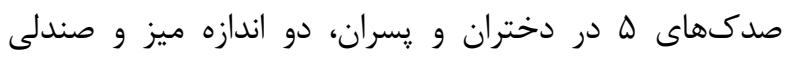

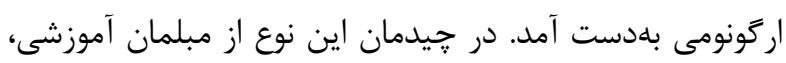

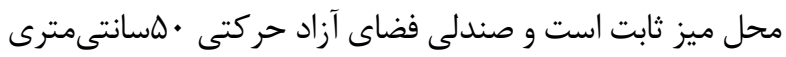

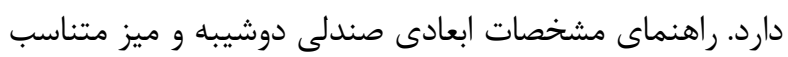


تعيين مشخصههاى آنترويومترى براى يسران و دختران و شكل وضعيت نشستن در حال استراحت و تكيه به صندلى (يوسجر

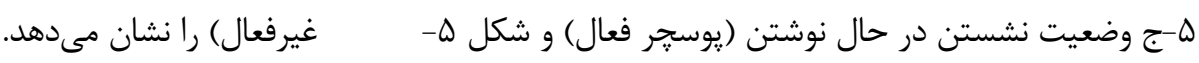
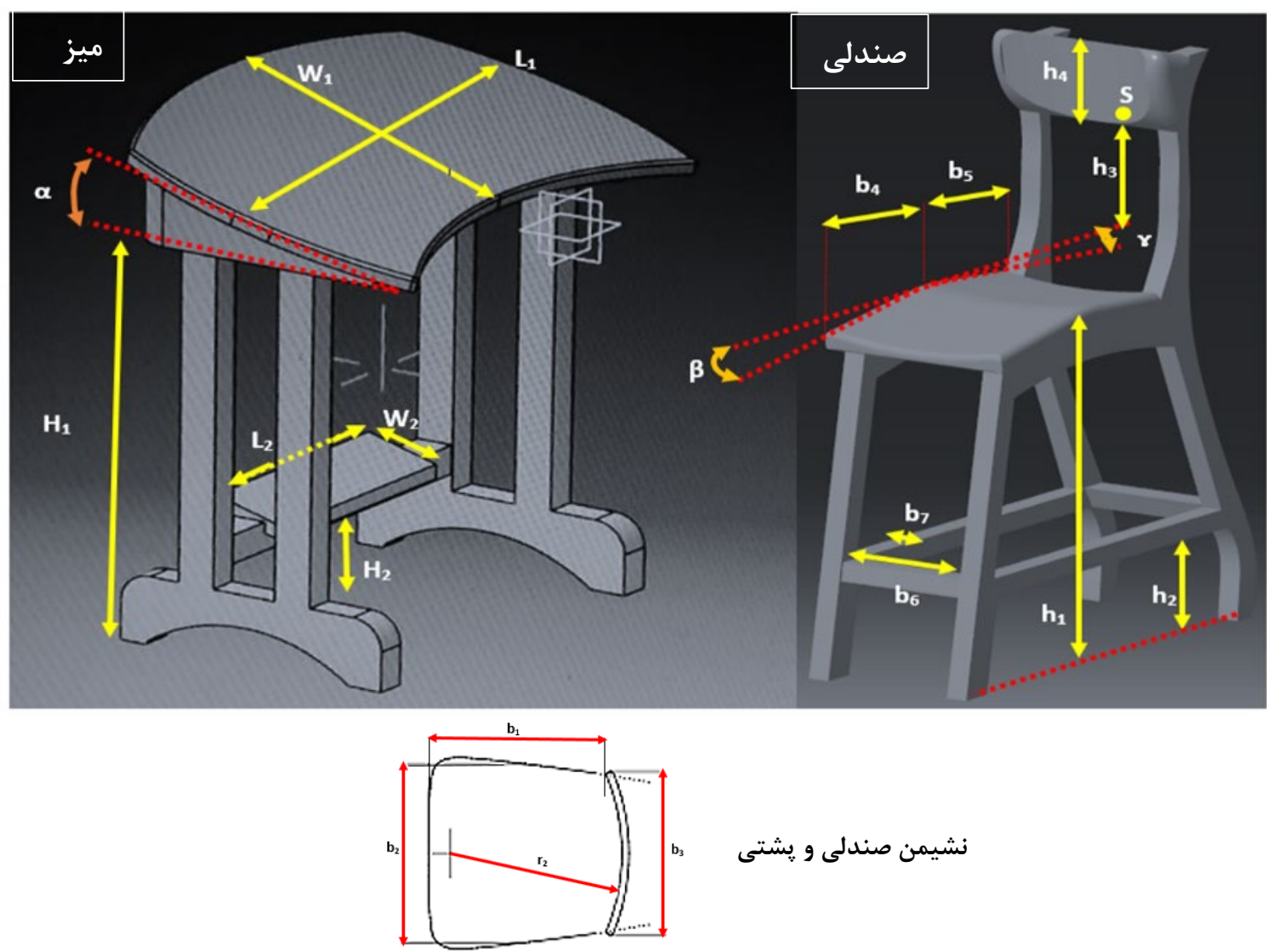

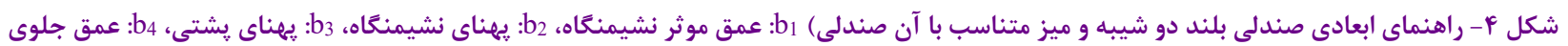

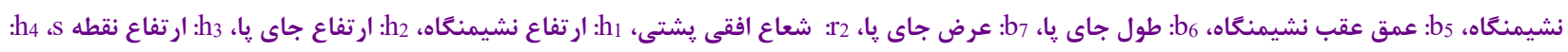

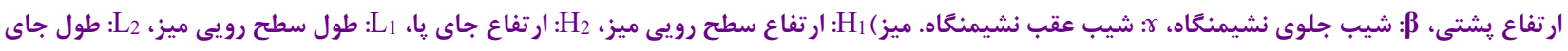

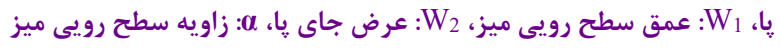

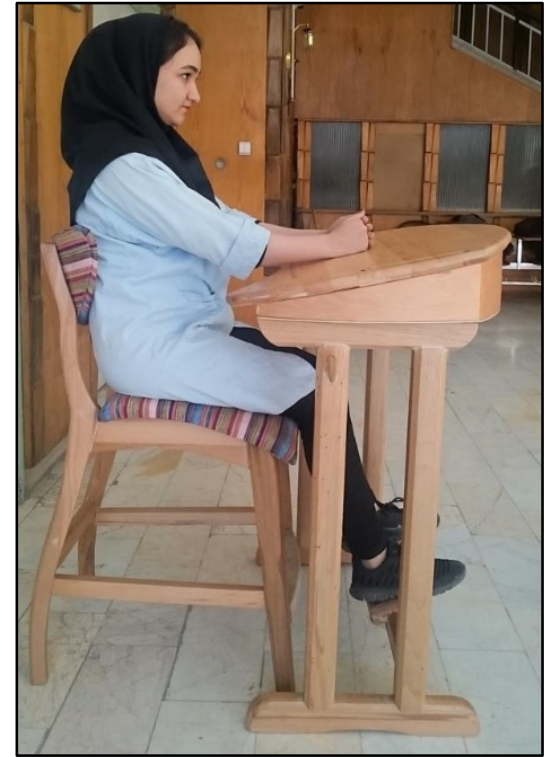

ب

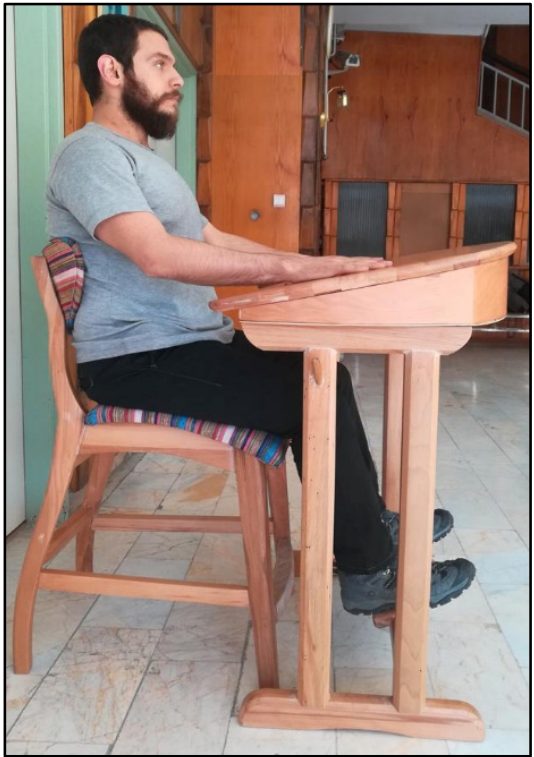

الف 


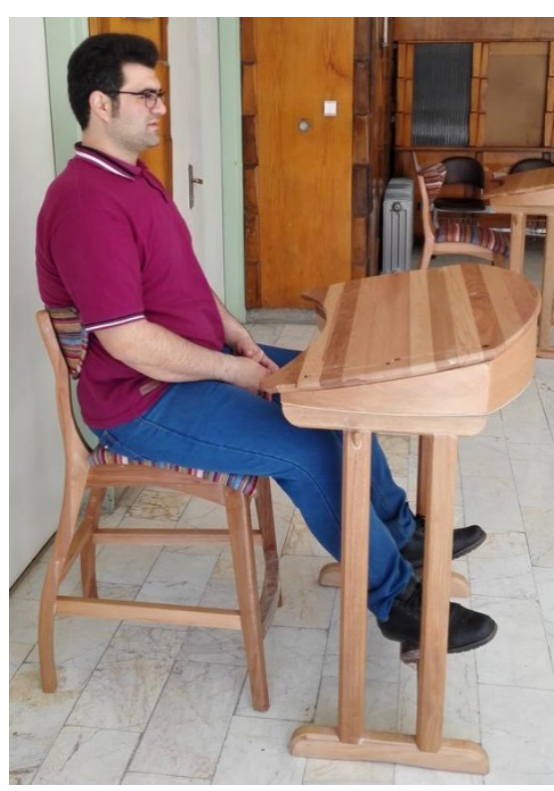

J

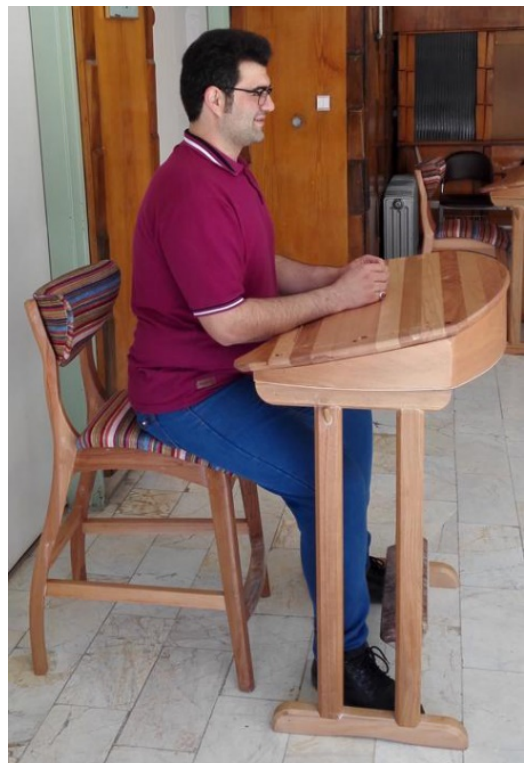

ج

شكل ه: الف و ب) ميز و صندلى اركَونومى طراحى و ساختهشده يس از تعيين مشخصههاى آنترويومترى براى يسران و دختران

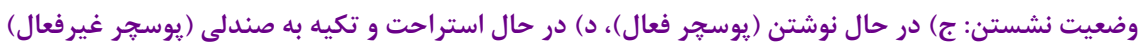

جدول ه: ابعاد ميز و صندلى اركونومى طراحى شده براى دانشجويان يرديس كشاورزى و منابع طبيعى دانشگاه تهران

\begin{tabular}{|c|c|c|c|}
\hline 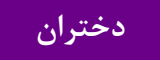 & 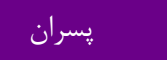 & متغيرها & محصول \\
\hline $1 \Delta \cdot \Delta-\mid V \mu \cdot$ & $1994-19 \ldots$ & محدوده تمامقد (mm) & \multirow{17}{*}{ 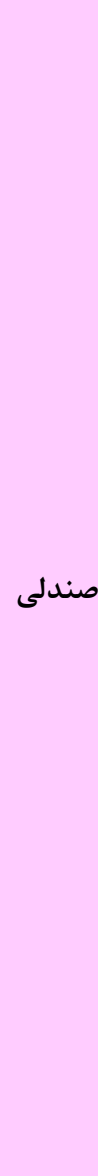 } \\
\hline rN- YN/GV & Fr- pq & محدوده ركبى(mm) & \\
\hline+1 . & +1 . & حداقل شيب قسمت جلو نشيمنكاه صندلى (درجه) & \\
\hline+10 & +10 & حداكثر شيب قسمت جلو نشيمنگحاه صندلى (درجه) & \\
\hline$-\Delta$ & $-\Delta$ & شيب قسمت عقب نشيمنكًاه صندلى (درجه) & \\
\hline GTr & 99. & ارتفاع نشيمنكاه (· • (I) بر حسب (mm) & \\
\hline Fr. & 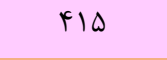 & عمق مؤثر نشيمنخاه(mm) & \\
\hline rq. & rVV & حداقل يهناى نشيمنگًاه(mm) & \\
\hline r.. & rqه & عمق سطح نشيمنَاه (حداقل) (mm) & \\
\hline $1 \wedge$ & $19 V$ & ارتفاع نقطه S ( • (1- تا •r+r)(mm) & \\
\hline 19. & 19. & ارتفاع يشتى(mm) & \\
\hline rr. & meV & حداقل يهناى يشتى (mm) & \\
\hline r.. & $r \cdot$. & حداقل شعاع افقى پشتى (mm) & \\
\hline $1 \cdot 4$ & $1 \cdot f$ & شيب يشتى (درجه) & \\
\hline tet & TY. & ارتفاع جاى پا(mm) & \\
\hline rA. & TY. & حداقل طول جاى پا(mm) & \\
\hline$\Delta \cdot$ & $\Delta \cdot$ & حداقل عرض جاى يا(mm) & \\
\hline
\end{tabular}




\begin{tabular}{|c|c|c|c|}
\hline 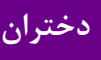 & 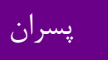 & متغيرها & 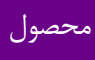 \\
\hline 94. & $99 \Delta$ & ارتفاع سطحرويى ميز(mm) & \multirow{7}{*}{ ميز } \\
\hline$\Delta .$. & $\Delta \cdots$ & حداقل عمق سطحرويى ميز(mm) & \\
\hline q.. & q.. & حداقل طول سطحرويى ميز براى هر نفر(mm) & \\
\hline TFT & rF. & ارتفاع جاى يا(mm) & \\
\hline r.. & 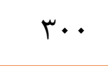 & حداقل طول جاى پا(mm) & \\
\hline $1 \cdots$ & $1 \cdots$ & حداقل عرض جاى پا ميز(mm) & \\
\hline$-r \cdot$ & $-r$ & حداكثر زاويه سطحرويى ميز (درجه) & \\
\hline
\end{tabular}

هستند و تقريباً تغييرات ابعاد بدنى آنان از كلاس اول ابتدايى تا انتهاى مقطع دبيرستان روبهافزايش است.

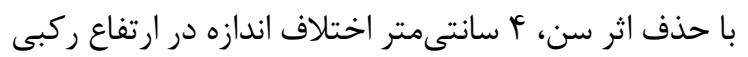

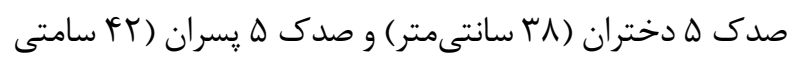

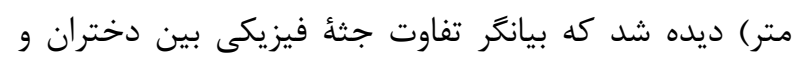

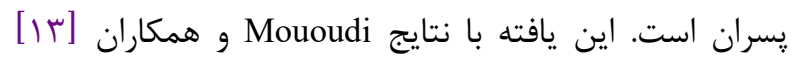

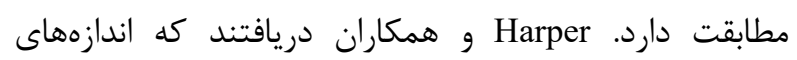

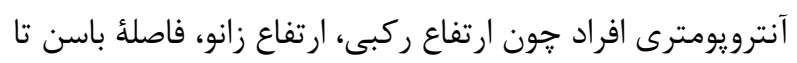

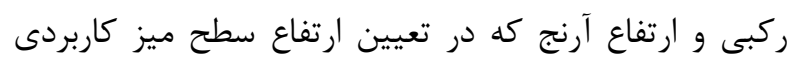

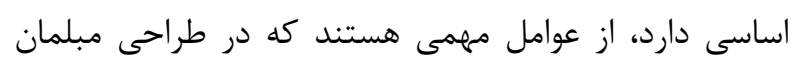

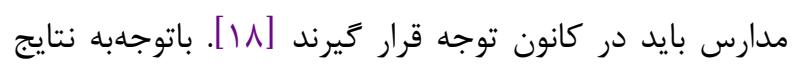
بلهدستآمده، مىتوان كفت كه ابعاد مبلمان آموزشى موجود در در

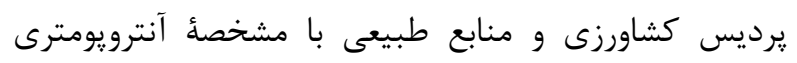

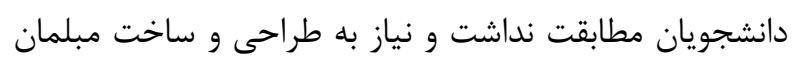

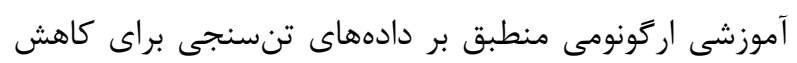
مشكلات MSD ضرورى و حياتى بهنظرمىرسد. البته نتايج

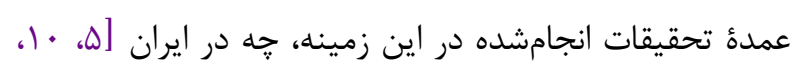
ז او r|]

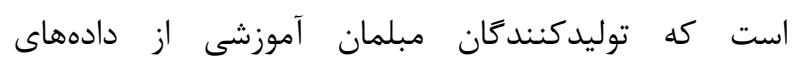
آنترويومترى براى طراحى و و ساخت استفاده نمى كنند. Mrimmer Milanese دولتى كه براساس دادهاى اركّونومى ساخته شدهاند، بهترين

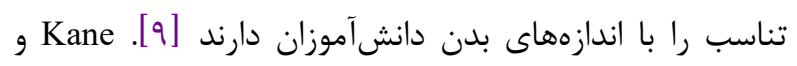

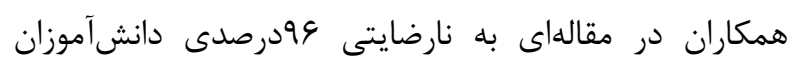

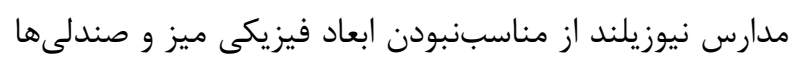

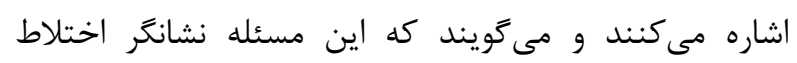
قوميتهاى مختلف در نيوزيلند است [19].
بلمدليل وجود تفاوتهاى ابعاد انسانى حتى در اقوام مختلف

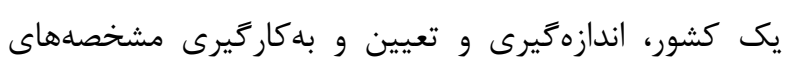

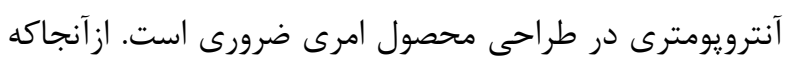

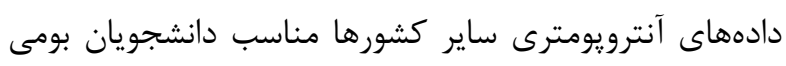

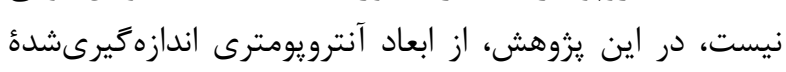

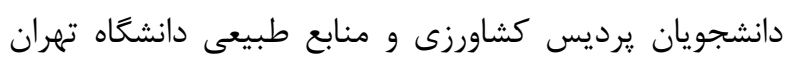

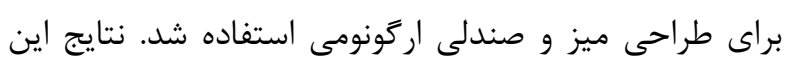

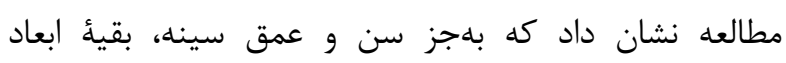

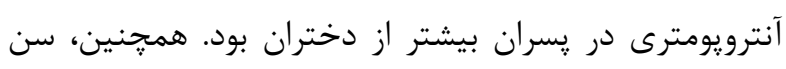

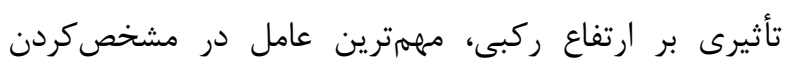

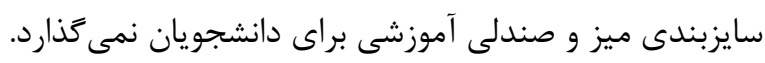

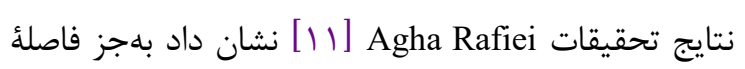

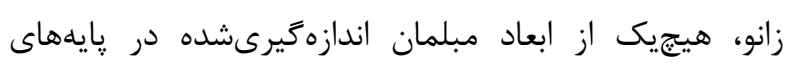

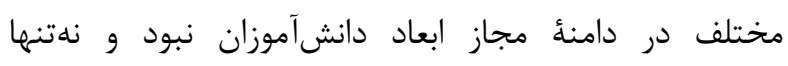

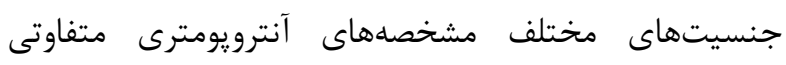

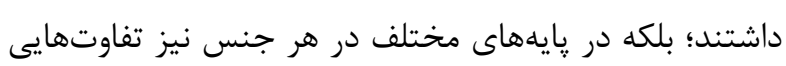

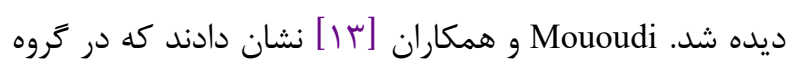

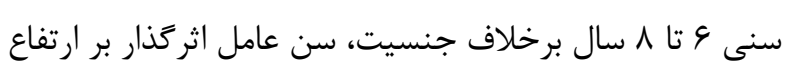

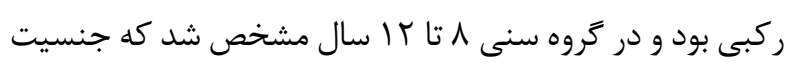

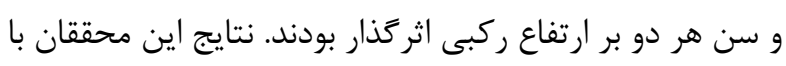

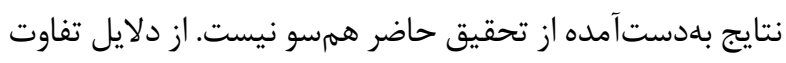

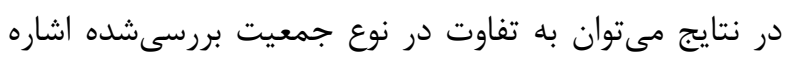

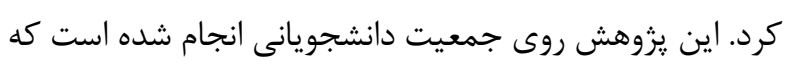

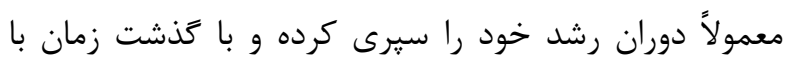

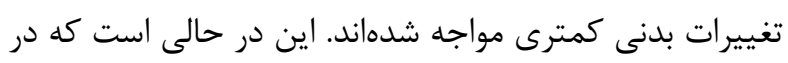

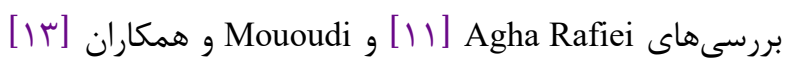
روى دانشآموزانى انجام شده است كه هنوز در دوران رشد 


\section{نتيجه تيرى}

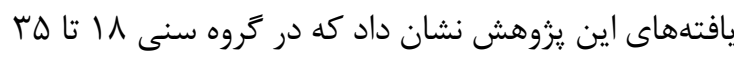

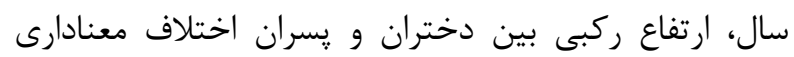

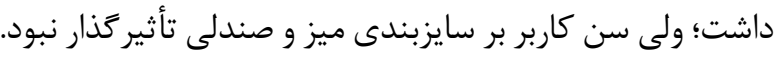

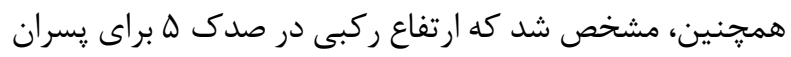

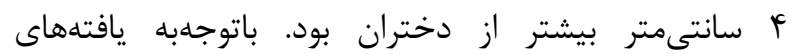

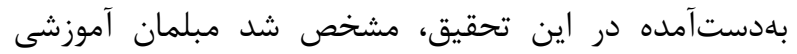
استفادهشه در يرديس كشاورزى و منابع طبيعى دانشعاه تهران با ابعاد بدنى دانشجويان متناسب نبود و نمى توان آنها دها را را مبلمان

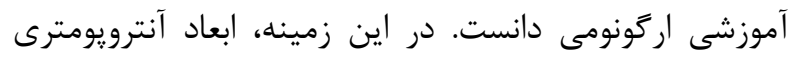

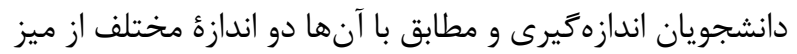
و صندلى اركونومى جدالزهم طراحى و ساخته شد؛ بهطورى كه دانشجويان بتوانند تغيير وضعيت بدنى بيشترى دارئر داشته باشند.

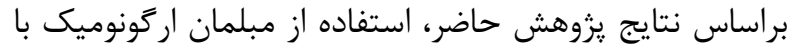

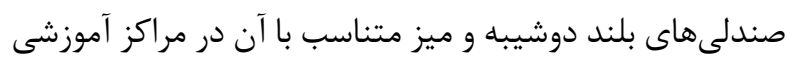

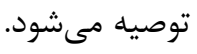
باتوجهبه انجام اين يزوهش در استان البرز و بهدليل تغيير

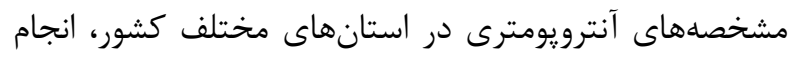

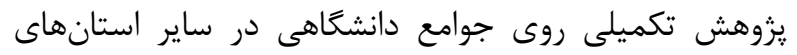

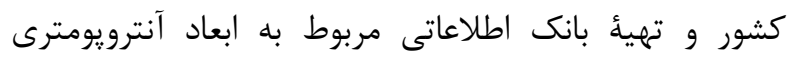
دانشجويان و طراحى مبلمان آموزشى اركونومى مطابق با بانيا

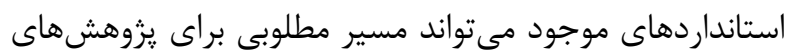
آتى دربارة اين موضوع باشد.

\section{تقدير و تشكر}

اين تحقيق در قالب پاياننامٔ كارشناسى ارشد با حمايت

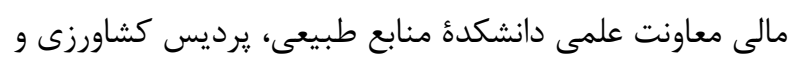

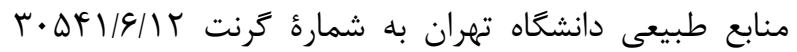

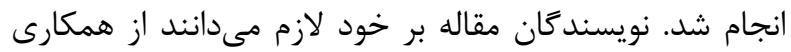

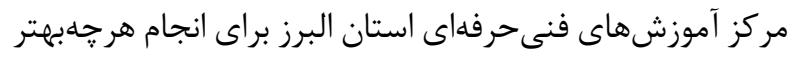
يزوهش تشكر و قدردانى كنند.

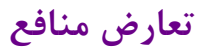

بين نويسندًان اين مقاله هيجَّونه تعارضى در منافع وجود

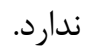

طراحى ميز و صندلى دانشجويان بايد بهكونهاى باشد كه

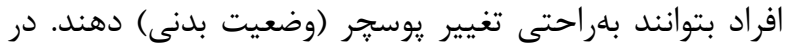

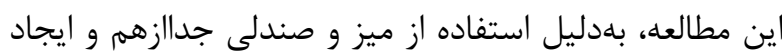

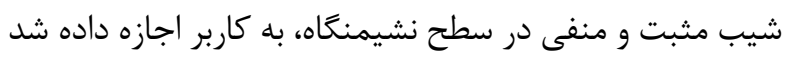
كه تغيير وضعيتهاى متفاوتى داشته باشد تا بتواند وضعيت بدنى ناراحت را به وضعيت راحت تغيير دهد. نتايج تحقيقات

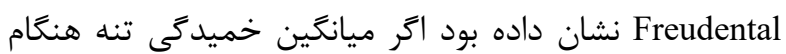
استفاده از ميزتحرير از צT به IN/T درجه كاهش يابد، مىتواند

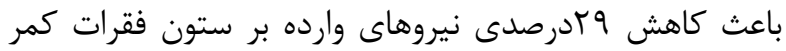

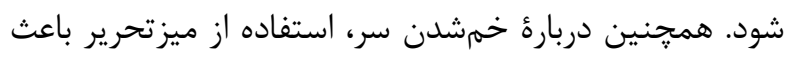

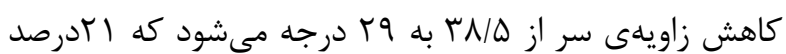

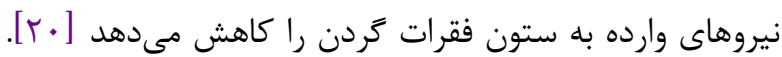
نشستن در يشت ميز و صندلى ها مشكلات اسكلتى عضلانى براى دانشجويان بهوجود مىآورد. بهعبارتديكر، محققان معتقدند كه مطلوبترين حالت زمانى است كه بدن انسان كاملاً عمود باشد. در اين يزوهش، باتوجهبه استاندارد ملى ايران (9697-1 INSO)

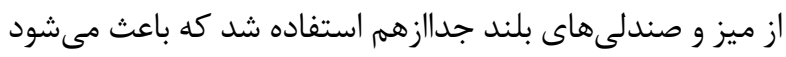

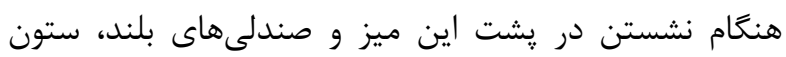

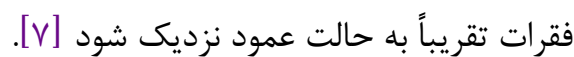
باتوجابه اينكه در يرديس كشاورزى و منابع طبيعى دانشعاه تهران، دانشجويان از تمامى شهرها و استانهاى كشور حضور دارند

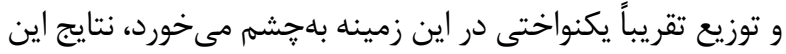

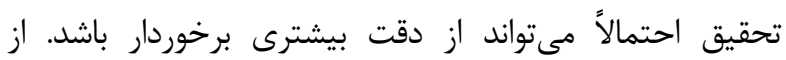

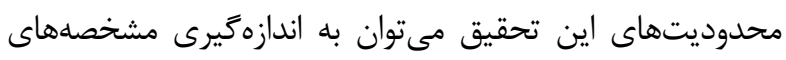
آنترويومترى و جمعآورى داده در دانشجويان دختر مطابق بهان باني شئونات اخلاقى و اسلامى اشاره كرد. در اين زمينه، از دو دانشجوى داني

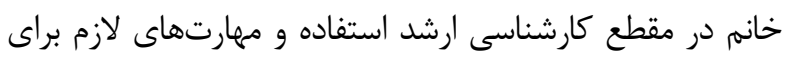

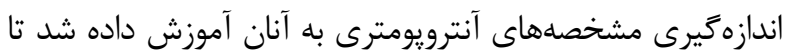
خطاى اندازمخيرى ناشى از خطاى انسانى بهحداقل برسد.

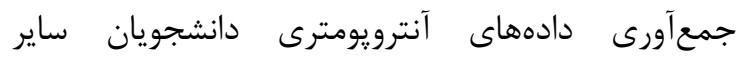
دانشعاههاى كشور براى تدوين استاندارد دقيق ايرانى، استفاده از ابعاد آنترويومترى بهدستآمده از دانشجويان در طراحى و ساخت ساير مبلمان مرتبط مانند ميز وصندلى رستورانهاى

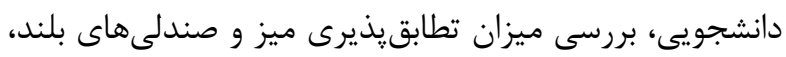

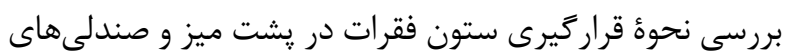
بلند با عكسبردارى راديوكرافى و طراحى و ساخت مبلمان

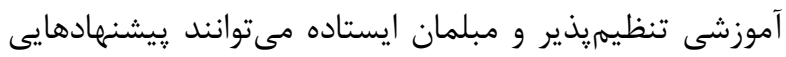
براى مطالعات آتى باشند. 


\section{References}

1. Sadeghi Naeini H, Erisian Z. Applied Anthropometry for product and environmental design, 1nd ed. Tehran: Jale Pub; 2016.

2. Panero J, Zelnik M. In: Ahmadinejhad M (Trans.). Human Dimension \& Interior Space. 1nd ed. Isfahan: Khak Pub; 2014.

3. Obinna FP, Sunday AA, Babatunde O. Ergonomic assessment and health implications of classroom furniture designs in secondary schools: A case study. Theor Issues Ergon Sci. 2020; 9:1-5. [DOI:10.1080/1463922X.2020.1753259]

4. Parvez MS, Rahman A, Tasnim N. Ergonomic mismatch between student's anthropometry and university classroom furniture. Theor Issues Ergon Sci. 2019; 20(5): 603-631. [DOI:10.1080/1463922X.2019.1617909]

5. Khoshabi P, Nejati E, Ahmadi SF, Chegini A, Makui A, Ghousi R. Developing a Multi-Criteria Decision-Making approach to compare types of classroom furniture considering mismatches for anthropometric measures of university students. PloS one. 2020; 15(9): e0239297. [DOI:10.1371/journal.pone.0239297] [PMID] [PMCID]

6. Dianat I, Karimi MA, Asl Hashemi A, Bahrampour $\mathrm{S}$. Classroom furniture and anthropometric characteristics of Iranian high school students: Proposed dimensions based on anthropometric data. Appl Ergon. 2013; 44(1): 101-108. [DOI:10.1016/j.apergo.2012.05.004] [PMID]

7. Mououdi MA, Choobineh AR. Ergonomics in practice: Selected essays on ergonomics. 6th ed. Tehran: Mad Pub; 2014.

8. Panagiotopoulou G, Christoulas K, Papanckolaou A, Mandroukas K. Classroom furniture dimensions and anthropometric measures in primary school. Appl Ergon. 2004; 35(2): 121-8. [DOI:10.1016/i.apergo.2003.11.002] [PMID]

9. Milanese S, Grimmer K. School furniture and the user population: An anthropometric perspective. Ergonomics. 2004; 47(4): 416-26. [DOI:10.1080/0014013032000157841] [PMID]

10. Dianat I, Karimi MA, Asl Hashemi A, Bahrampour $\mathrm{S}$. Classroom furniture and anthropometric characteristics of Iranian high school students: Proposed dimensions based on anthropometric data. Appl Ergon. 2013; 44(1): 101-8. [DOI:10.1016/j.apergo.2012.05.004] [PMID]

11. Agha Rafiei E, Parsapazhouh D, Khani Jazani R, Ebrahimi G, Khodadadeh Y. Evaluation of mismatch between school furniture dimensions and students' anthropometric characteristics in Karaj primary schools, Iran. Iran J Nat Resour. 2008; 61(3): 693-711.

12. Heidari Moghadam R, Motamedzade M, Roshanaei Gh, Ahmadi R. Match between school furniture dimensions and children's anthropometric dimensions in male elementary schools. Iran $\mathrm{J}$ Ergon. 2014; 2(1): 9-18.

13. Mououdi MA, Mousavinasab SN, Gramian SMR, Akbari J. Anthropometric evaluation of primary school students in the Mazandaran province for the design of school furniture. Iran J Ergon. 2016; 4(1): 47-55. [DOI:10.21859/joe-04016]

14. Rajabi Shameli E, Sheikhhoseini R, Asadi Melerdi $\mathrm{S}$. The relationship between the school furniture dimensions and trunk alignment with musculoskeletal disorders in boy students in Karaj. Iran J Ergon. 2019; 10;7(3): 24-32.

15. Stephen P. Anthropometry, ergonomics and the design of work. 2nd ed. London: Taylor and Francis Pub; 2005.

16. Odunaiya NA, Owonuwa DD, Oguntibeju OO. Ergonomic suitability of educational furniture and possible health implications in a university setting. Adv Med Educ Pract. 2014; 5: 1-14. [DOI:10.2147/AMEP.S38336] [PMID] [PMCID]

17. Mououdi MA, Choobineh AR. Bodyspace: Anthropometry, ergonomics and the design of work. 10th ed. Tehran: Mad Pub; 2017: 103-117.

18. Harper K, Mallin D, Marcus N, McElheny M, Miller T, Navai M, et al. Ergonomic evaluation of the KinderZeat child seat in a preschool setting. Class Project Report; 2002: 1-18.

19. Kane PJ, Pilcher M, Legg SJ. Development of a furniture system to match student needs in New Zealand schools. In 16th World Congress on Ergonomics; 2006: 10-14.

20. Freudental A, Riel MD, Molenbroek JF, Snigders GJ. The effect on sitting posture of a desk with a ten-degree inclination using on adjustable chair and table. Appl Ergon. 1991; 22(5): 329-336. [DOI:10.1016/0003-6870(91)90389-Y] 